\title{
Transmission Line Security Monitor: Final Report
}

\author{
John Svoboda
}

April 2011

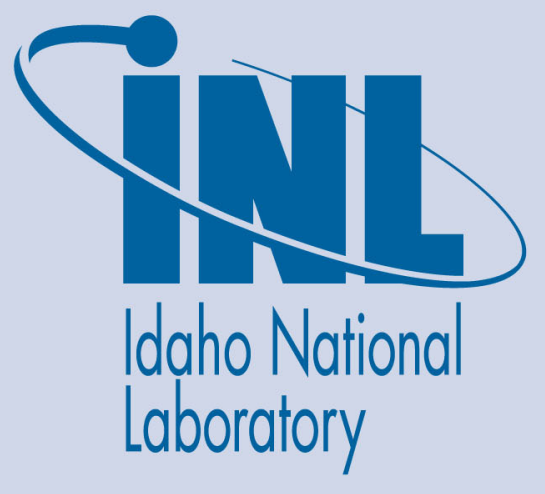

The INL is a U.S. Department of Energy National Laboratory operated by Battelle Energy Alliance 


\section{DISCLAIMER}

This information was prepared as an account of work sponsored by an agency of the U.S. Government. Neither the U.S. Government nor any agency thereof, nor any of their employees, makes any warranty, expressed or implied, or assumes any legal liability or responsibility for the accuracy, completeness, or usefulness, of any information, apparatus, product, or process disclosed, or represents that its use would not infringe privately owned rights. References herein to any specific commercial product, process, or service by trade name, trade mark, manufacturer, or otherwise, does not necessarily constitute or imply its endorsement, recommendation, or favoring by the U.S. Government or any agency thereof. The views and opinions of authors expressed herein do not necessarily state or reflect those of the U.S. Government or any agency thereof. 


\title{
Transmission Line Security Monitor: Final Report
}

\author{
John Svoboda
}

April 2011

Idaho National Laboratory Idaho Falls, Idaho 83415

http://www.inl.gov

\author{
Prepared for the \\ U.S. Department of Energy \\ Office of Nuclear Energy \\ Under DOE Idaho Operations Office \\ Contract DE-AC07-05ID14517
}




\section{SUMMARY}

The Electric Power Transmission Line Security Monitor System Operational Test is a project funded by the Technical Support Working Group (TSWG). TSWG operates under the Combating Terrorism Technical Support Office that functions under the Department of Defense. The Transmission Line Security Monitor System is based on technology developed by Idaho National Laboratory. The technology provides a means for real-time monitoring of physical threats and/or damage to electrical transmission line towers and conductors as well as providing operational parameters to transmission line operators to optimize transmission line operation. The end use is for monitoring long stretches of transmission lines that deliver electrical power from remote generating stations to cities and industry. These transmission lines are generally located in remote transmission line corridors where security infrastructure may not exist. Security and operational sensors in the sensor platform on the conductors take power from the transmission line and relay security and operational information to operations personnel hundreds of miles away without relying on existing infrastructure. Initiated on May 25, 2007, this project resulted in pre-production units tested in realistic operational environments during 2009, 2010, and 2011. A technology licensee, Lindsey Manufacturing of Azusa California, is assisting in design, testing, and ultimately production. The platform was originally designed for a security monitoring mission, but it has been enhanced to include important operational features desired by electrical utilities. 


\section{CONTENTS}

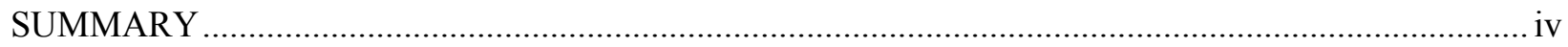

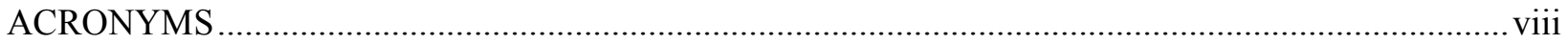

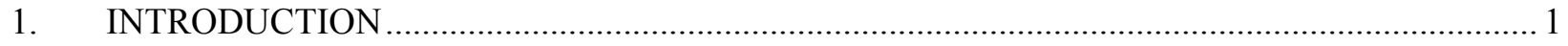

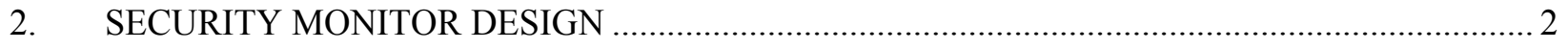

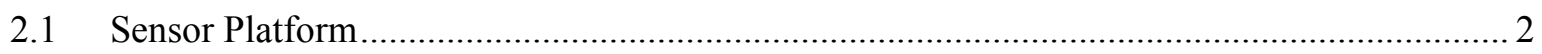

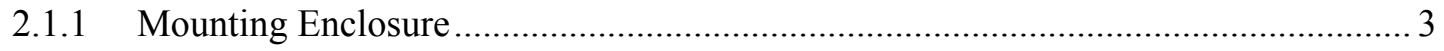

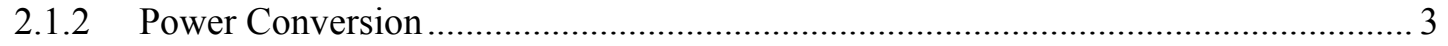

2.1.3 Infrared Sensor (Ground Level Motion Detection) .............................................. 3

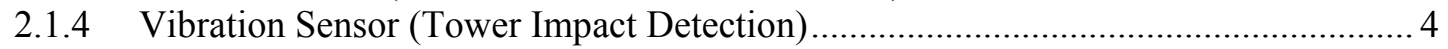

2.1.5 Conductor Tilt and Angle (Sag Detection) .................................................... 4

2.1.6 Electronics/Conductor Temperature (System Health) ......................................... 5

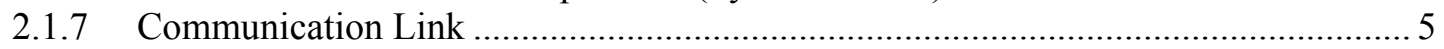

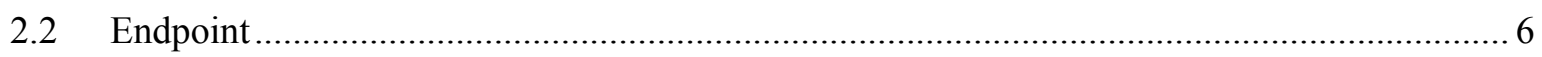

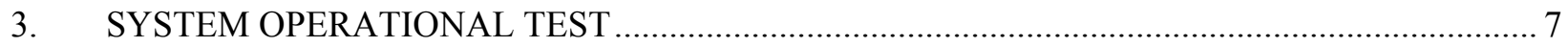

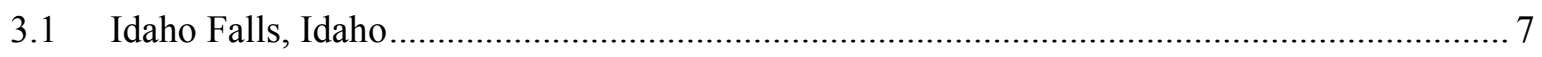

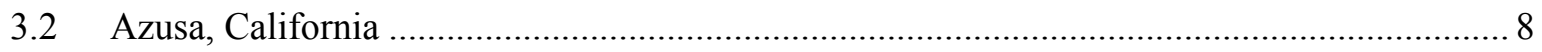

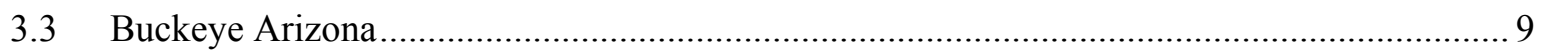

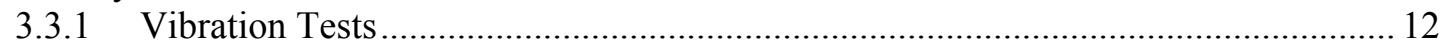

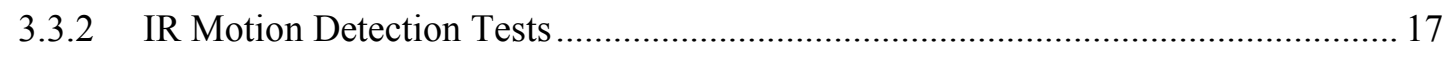

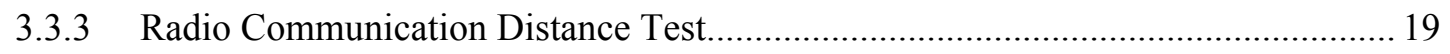

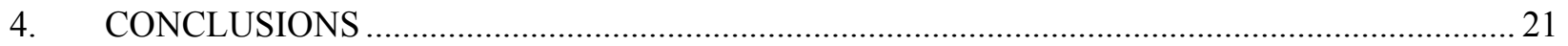

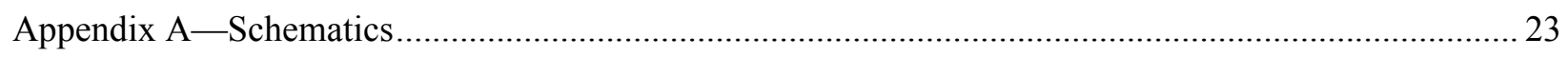

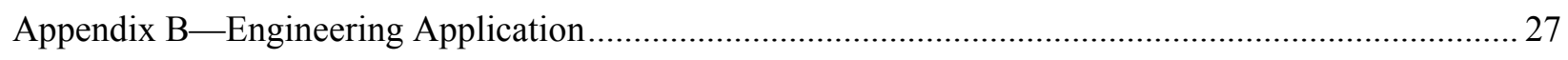

Appendix C - Tower Impact Testing Vibration Spectrum …........................................................... 33

\section{FIGURES}

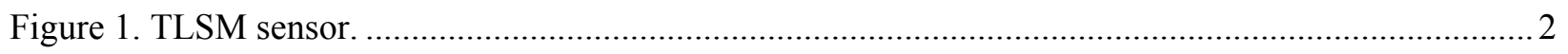

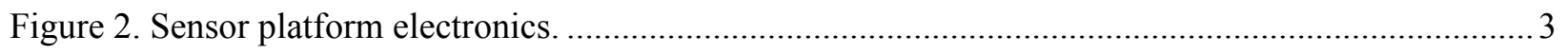

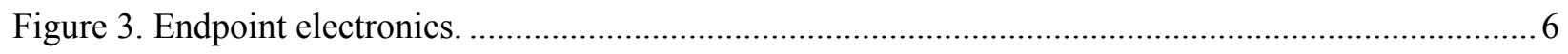

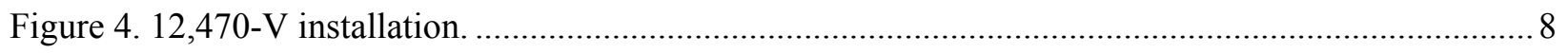

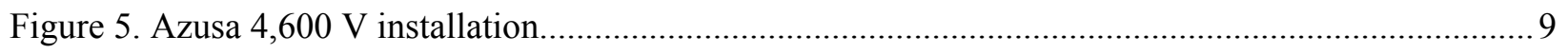

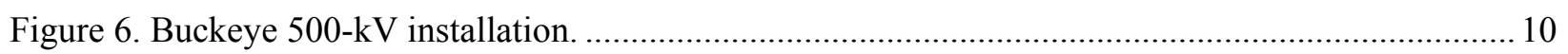

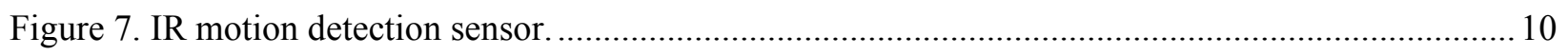

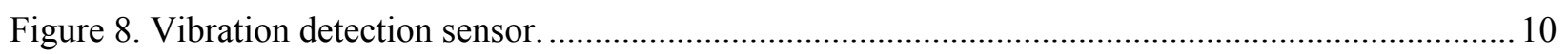




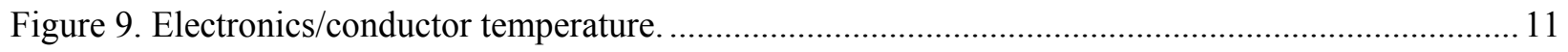

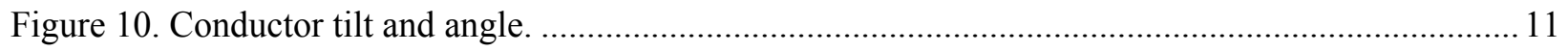

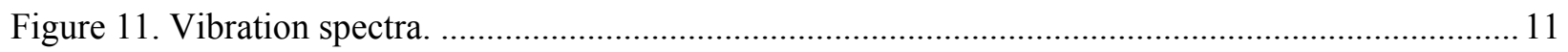

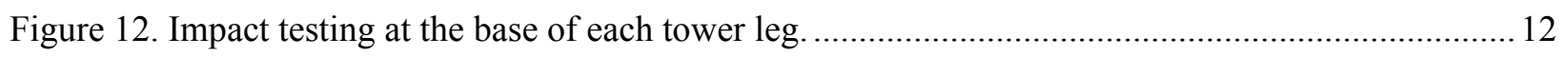

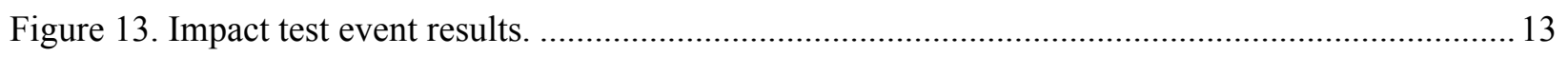

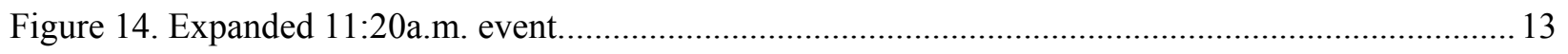

Figure 15. Southwest leg, west face, 1-meter elevation, 5.3 to 11.4 joule impulse................................. 14

Figure 16. Southwest leg, south face, 1 -meter elevation, 5.3 to 11.4 joule impulse................................. 15

Figure 17. Northeast leg, north face, 1 meter, 5.3 to 11.4 joule impulse................................................ 15

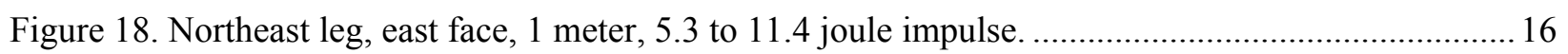

Figure 19. Southwest leg, west face, 1.47 meter, 5.3 to 11.4 joule impulse repeat. ................................ 16

Figure 20. Southwest leg, west face, 0.4 meter, 5.3 to 11.4 joule impulse repeat. .................................. 17

Figure 21. Southwest leg, west face, 0.4 meter (bolt level), 5.3 to 11.4 joule impulse repeat................... 17

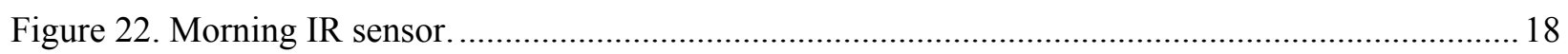

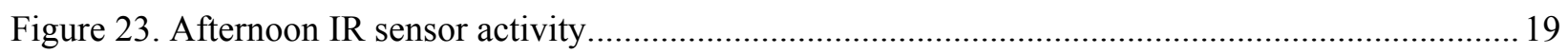

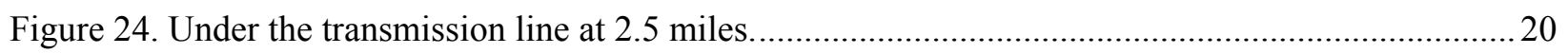

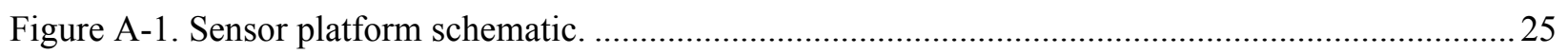

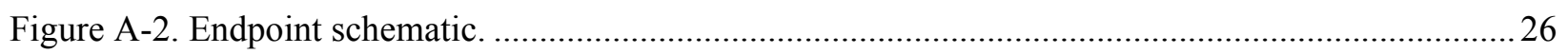

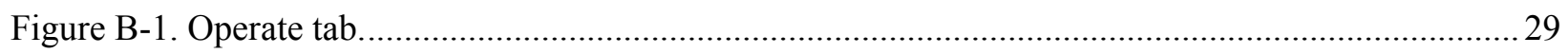

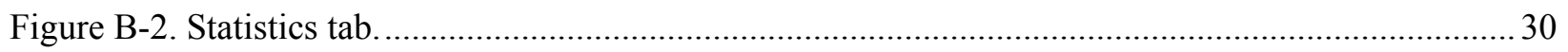

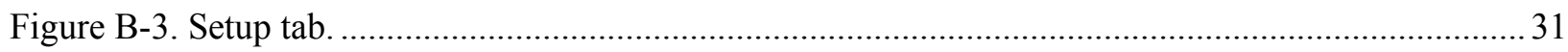

Figure $\mathrm{C}-1$. Southwest leg, west face, 1 meter, 5.3 and 11.4 joule impulse......................................... 35

Figure $\mathrm{C}-2$. Southwest leg, south face, 1 meter, 5.3 and 11.4 joule impulse. ........................................ 36

Figure $\mathrm{C}-3$. Northwest leg, north face, 1 meter, 5.3 and 11.4 joule impulse.......................................... 36

Figure $\mathrm{C}-4$. Northwest leg, west face, 1 meter, 5.3 and 11.4 joule impulse.......................................... 37

Figure $\mathrm{C}-5$. Northeast leg, north face, 1 meter, 5.3 and 11.4 joule impulse........................................... 37

Figure $\mathrm{C}-6$. Northeast leg, east face, 1 meter, 5.3 and 11.4 joule impulse............................................. 38

Figure C-7. Southeast leg, east face, 1 meter, 5.3 and 11.4 joule impulse............................................. 38

Figure $\mathrm{C}-8$. Southeast leg, east face, 1 meter, 5.3 and 11.4 joule impulse.............................................. 39

Figure C-9. Southeast leg, east face, 1 meter, 5.3 and 11.4 joule impulse repeat. ................................... 39

Figure $\mathrm{C}-10$. Southwest leg, west face, 1.47 meter, 5.3 and 11.4 joule impulse repeat...........................40

Figure C-11. Southwest leg, west face, 0.4 meter, 5.3 and 11.4 joule impulse repeat. ............................ 40 


\section{ACRONYMS}

CRADA Cooperative Research and Development Agreement

DC Direct Current

$\mathrm{dIR} / \mathrm{dt} \quad$ Derivative of Infrared radiation with respect to Time.

DSP Digital Signal Processor

FFT Fast Fourier Transform

GSM Global System for Mobile Communications

$\mathrm{Hz} \quad$ Hertz

INL Idaho National Laboratory

IR Infrared

ISM Industrial Scientific and Medical

$\mathrm{mW} \quad$ Milli-Watt

PC Personal Computer

$\mathrm{RF} \quad$ radio frequency

SO System Operational

TLSM Transmission Line Security Monitor

TSWG Technical Support Working Group

VPN Virtual Private Network 


\section{Transmission Line Security Monitor: Final Report 1. INTRODUCTION}

The electric power Transmission Line Security Monitor (TLSM) System is fundamentally a communications network of small, inexpensive, low-power electronic sensor platforms that are mounted on 1 conductor at each tower of an electric power transmission or distribution system. Each platform has the ability to (a) measure conductor borne impact vibrations generated by tower tampering, (b) sense infrared (IR) human body heat within a set of windows defined at the base of each tower, (c) measure conductor temperature, (d) measure conductor tilt, (e) measure conductor angle, (f) measure conductor height above objects, (g) communicate sensor information to transmission line endpoints located where communication infrastructure exists, (h) derive platform power from the transmission line, (i) store energy for use by the sensor platform when power is interrupted without the use of batteries, and (j) communicate all information to transmission line operators through the use of endpoints. A typical installation could require one to several hundred sensor platforms and one or more endpoints. The number of endpoints is dependent on the number of points along the transmission line where data is desired to be extracted from the network and presented to the transmission line control room. An event recorded by the sensors that is indicative of tower tampering would cause the platform to "wake up" or activate and generate a message containing event information and tower identification. The message is then transmitted via a short-range radio frequency (RF) link to the two platforms located on the two adjacent towers. The platforms located on the adjacent towers wake up in response to the message and transmit the information to the next tower. This process continues until the message reaches an endpoint where it can be communicated to authorities in charge of operating the transmission line or providing security.

TLSM development started at the Idaho National Engineering Laboratory (INL) during 2004. The technology was licensed to Lindsey Manufacturing of Azusa, California during 2007. Also during 2007 TSWG funded final development of the technology to the point of commercialization. A patent "Methods, Apparatus, and Systems for Monitoring Transmission Systems", US Patent No. 7786894 was awarded to the INL during 2010. Documented in this report are the TLSM system operational test results that close out the INL contract with TSWG. 


\section{SECURITY MONITOR DESIGN}

The TLSM design used for the System Operational (SO) test was the design installed on the Palo Verde power generating West Wing 500-kV line that passes through the Tartesso Development in Buckeye Arizona (see Figure 1). The TLSM consists of two major components: a sensor platform and an endpoint. The sensor platform is typically mounted on a transmission line conductor close to the

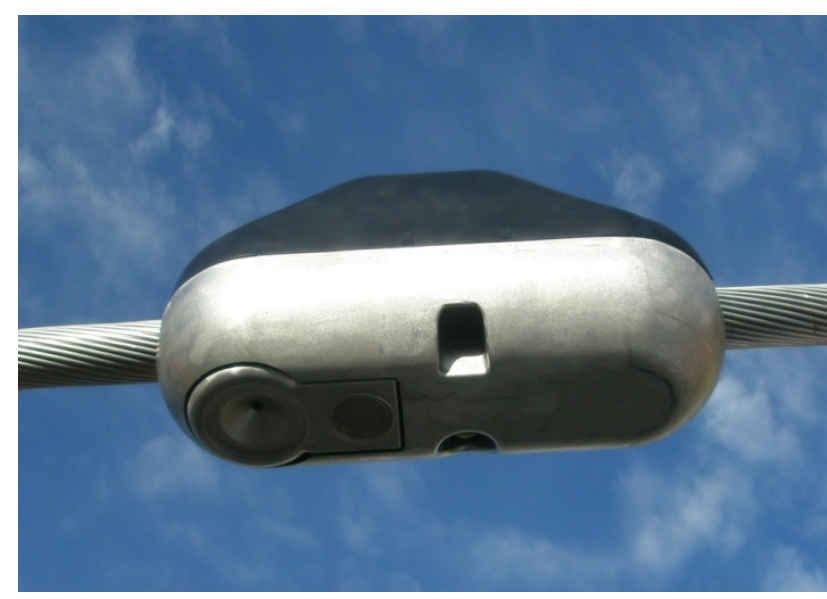

Figure 1. TLSM sensor. transmission line tower suspending the conductor. One sensor platform is located at each tower of a typical transmission line. The tower location was chosen such that the platform can provide a surveillance function at the base of each tower to detect abnormal activity related to damage to the base of the tower. A typical transmission line may have several hundred towers providing power from the generating station to the load. The platform detects this activity and relays the information from tower to tower until it reaches an endpoint where the information is delivered to the platform transmission line control room operators. Endpoint to control room communication takes place over existing infrastructure such as cell or land line telephone connections, Internet,

satellite, or any other communication infrastructure. The sensor platform also provides operational capability in addition to its original security function. Operational use may require locating the sensor platform midspan to detect line to ground distances at the transmission line's lowest point. Line to ground monitoring is very important when considering maximum power transmission through the conductors. The sensor platform and the endpoint designs are discussed in the remainder of this section.

\subsection{Sensor Platform}

The sensor platform provides the sensing and communication functionality of the TLSM. The heart of the monitor is a 2.3 in. $\times 4$ in. electronics circuit board (see Figure 2) consisting of power conversion electronics, sensor interface electronics, two Digital Signal Processors (DSPs), and a digital communications radio. One DSP services the sensors and the other services the communications radio. The board is housed in an enclosure that is capable of attaching to a transmission line conductor. Sensing functions relevant to transmission line security include detecting movement at the base of a tower through IR (Infrared) motion detection and detecting conductor borne vibrations indicative to tampering at the base of a tower. Sensing functions relevant to electrical transmission line operation include detecting conductor sag, conductor to ground distance, and conductor temperature. Operational functions were added later in the monitor's development based on conversations with utilities discussing their needs relevant to electrical power delivery. These functions were low-cost developments that were mostly based on analysis of already acquired data. Sensing functions relevant to sensor platform operation include electronics temperature, energy storage, and data packet transmission statistics. See Appendix A, "Schematics," for schematics of the original sensor platform and endpoint. 


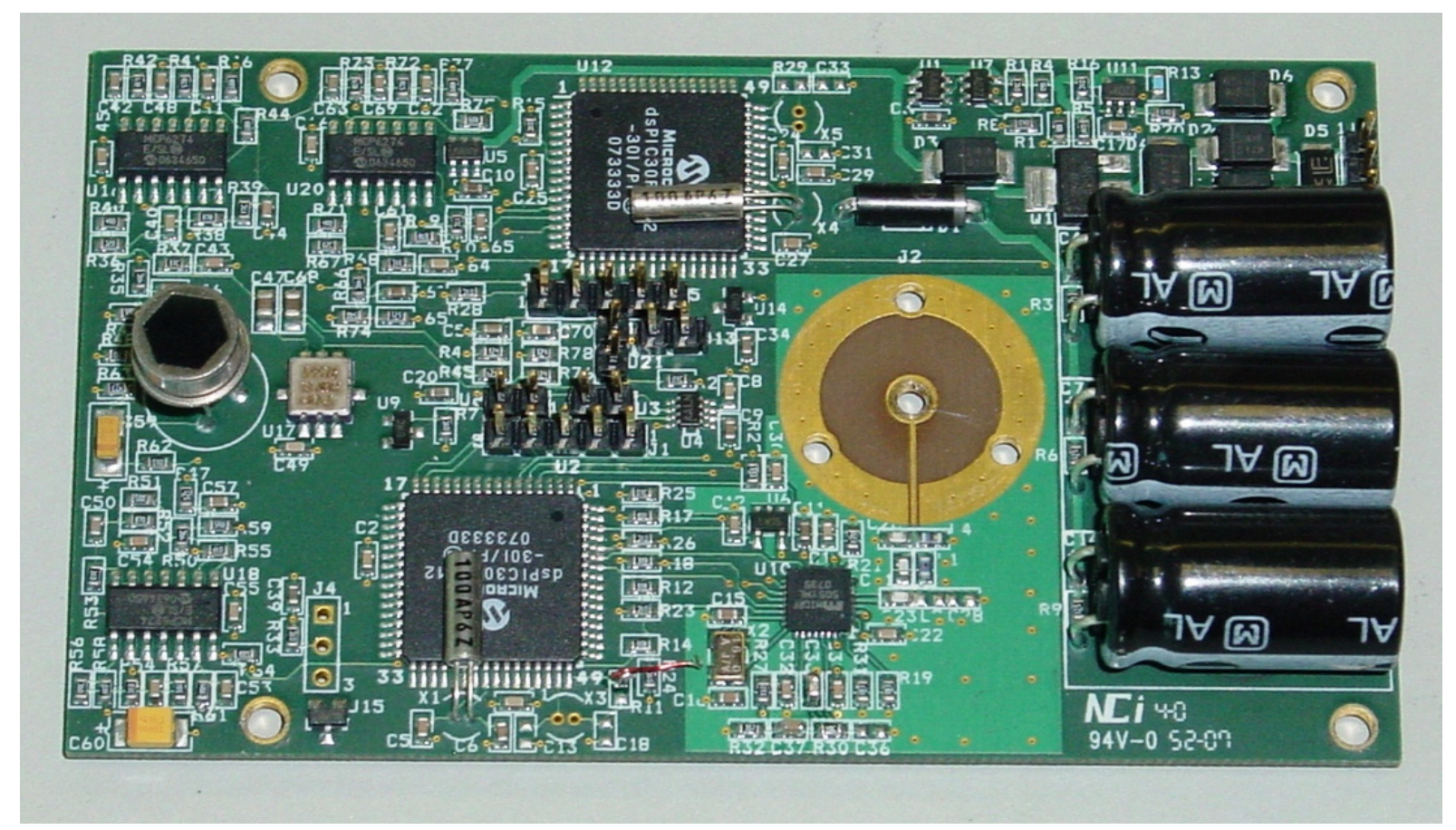

Figure 2. Sensor platform electronics.

\subsubsection{Mounting Enclosure}

The heart of the system is the electronics package. It is located on a high-voltage transmission line that may have a line to ground potential up to or even greater than $500 \mathrm{kVac}$. The package is required to be protected from weather and the effects of corona. The mounting enclosure provides these two requirements and must be vibration free and "hot stick" deployable to prevent de-energizing the transmission line when installing the sensor platform. The enclosure must accommodate mounting on conductors ranging from $0.75 \mathrm{in}$. to greater than $2.0 \mathrm{in}$. Lindsey Engineering provided this functionality with their mounting enclosure (see Figure 1).

\subsubsection{Power Conversion}

The platform derives its power from the current flowing through the conductor that it is attached to. Transmission line conductor current $(\sim 150$ to $1500 \mathrm{~A})$ creates a $60 \mathrm{~Hz}$ magnetic field that is coupled to a current transformer located in the mounting enclosure. The transformer converts the magnetic field to a small current and voltage used to power the low power platform electronics. The transformer has a split core that accommodates clamping the core around the conductor. It is important that the transformer does not induce vibrations into the mounting enclosure that may be picked up by the vibration sensor and interpreted as conductor-borne vibrations. The minimum transmission line current required to operate the sensor platform is about $150 \mathrm{~A}$. This allows the platform to be mounted on distribution lines commonly found within cities and in rural areas where the voltage is low but the current is high. Power for the platform does not depend on conductor voltage, just current. Converted electrical energy is stored in on-board energy storage devices and used to power the platform for a few seconds after a loss of power. The on-board energy storage is measured, recorded, and reported. The platform does not require the use of any on-board consumables such as batteries, so routine maintenance is not required.

\subsubsection{Infrared Sensor (Ground Level Motion Detection)}

A pyroelectric infrared sensor with an infrared passband from 4 to 12 microns, an IR lens, and a passband filter provide the motion detection interface to the sensor DSP. The IR sensor sensitivity is 
located in the human body's blackbody radiation range giving a warm object (human or animal) a high contrast against a warmer or colder background. The sensor responds to a change in radiation (dIR/dt) over a period of time within its passband that detects movement as opposed to detecting the absolute level of IR radiation. This characteristic gives the sensor the ability to detect movement in hot or cold or night or day conditions. A specifically designed IR lens with a focal length of about $60 \mathrm{ft}$ is used to focus an object the size of the human body as viewed from above and located at the base of the tower on the sensing elements. An electrical passband filter with gain is used to amplify the low-level signal from the sensor and reject changes in output that are out of band with the expected movement of warm bodies at the base of the tower.

The output of the sensor, lens, and electronics is delivered to the DSP where further processing takes place to reject naturally occurring IR changes. The IR sensor alone does not allow for detecting the difference between a human and animal, but when coupled with the detection of non-natural high energy impulse vibrations the probability of detecting tampering at the base of the tower increases. The computed values for $\mathrm{dIR} / \mathrm{dt}$ are compared to a threshold and values that exceed the threshold are reported to the operator via the onboard radio link and the endpoint.

\subsubsection{Vibration Sensor (Tower Impact Detection)}

A two-axis accelerometer (vibration sensor) and two passband filters provide the vibration detection interface to the sensor DSP. The vibration sensors are located on the circuit board and oriented such that vibrations in the plane of the board are measured relative to the axial direction of the transmission line conductors. Two passband filters with gain are used to amplify the vibration signals and reject all out of band signals that are not considered to be caused by tower tampering. The resulting signals are delivered to the sensor DSP where the sensor time domain signals are converted to the frequency domain through the application of a Fast Fourier Transform (FFT). Once in the frequency domain, known vibrations not related to tampering can be effectively filtered out through simple addition and subtraction. Signals removed include those related to the transmission line $60-\mathrm{Hz}$ fundamental and its harmonics. The resulting frequency spectra is then summed and compared to a threshold, and the values that exceed the threshold are reported to the operator via the onboard radio link and the endpoint.

\subsubsection{Conductor Tilt and Angle (Sag Detection)}

The two-axis accelerometer that is used to perform frequency domain vibration spectral measurements can also provide accelerometer tilt and angle measurements if the direct current (DC) component of the FFT vibration spectrum is examined. Tilt is defined to be the conductor angle measured from the horizontal plain in the vertical direction. As the conductor sags, the conductor tilt angle increases. Angle is defined to be the angular displacement of the conductor from the vertical plain measured from the insulator attachment point. As a horizontal wind blows perpendicular to the conductor axial direction the conductor angle increases.

Accelerometer tilt and angle measurements can be directly related to the tilt and angle of the conductor since the sensor platform is mounted on the conductor at the tower. Given prior knowledge of the tower, conductor, and ground geometry coupled with measurements of conductor the tilt and angle, the height of the conductor above ground (conductor sag) at the lowest point in the span can be calculated or inferred.

Conductor sag is not directly related to protecting the electrical transmission line infrastructure from acts of sabotage or vandalism. It is directly related to the safe operation of transmission lines during times of stress such as that occurring during the loss of a transmission line or loss of generation capacity on the grid. During these times, knowledge of excess transmission line capacity can be a critical parameter in determining how to reroute power to critical loads without resorting to brown outs or black outs. Real time knowledge of conductor sag at each tower provides the transmission line operators with information critical to maintaining the transmission lines within their safe operating limits during times of normal and 
abnormal conditions. Currently, the information used for this purpose is inferred from computer-based transmission line models coupled with information on local weather conditions. This measurement was added to the sensor platform at the request of transmission line operators.

\subsubsection{Electronics/Conductor Temperature (System Health)}

Two temperature measurements (electronics circuit board and transmission line conductor) are included as part of the sensor platform. The electronics circuit board measurement is used as a measure of platform health. The transmission line conductor measurement is used as a direct measure of transmission line capacity.

The electronic components are generally specified to perform within the temperature range from -40 to $+85^{\circ} \mathrm{C}$. Board temperature measurements indicate when these limits are approached or exceeded. Ideally they would never be exceeded. The board temperature measurement relies on heat conducted from the circuit board to the temperature sensor that is in contact with the board.

Conductor temperature ratings are well characterized and are a major factor to consider when designing transmission lines due to conductor sag and long-term loss of strength. Sensor platform conductor temperature measurements are implemented using a non-contacting optical pyrometer that measures temperature by examining emissions in the IR spectrum. Conductor temperature can be used to augment conductor sag calculations.

Conductor temperature measurements, like conductor sag, are also not directly related to protecting the transmission line infrastructure, but are directly related to safe operation of transmission lines during times of stress.

\subsubsection{Communication Link}

Each TLSM is intended to be mounted on a conductor close to the insulator holding it at each tower of a transmission line or a section of a transmission line. From this vantage point it can detect warm body movement at the base of each tower and vibrations associated with that tower. When thresholds are exceeded a message is generated and transmitted to the transmission line control room to alert operations that a possible threat to a tower is occurring. The distances between the operator and the alarming TLSM can be several hundred miles away as wells as in areas where communication infrastructure does not exist. To implement communication each TLSM contains an RF transmitter that is capable of acting as a network node in a one-dimensional network transmitting information from each sensor to the operators.

Each TLSM contains a one Watt Industrial Scientific and Medical (ISM) band transceiver operating between 902 and $928 \mathrm{MHz}$. The transceiver supports 38,400-baud rate, 256-bit Advanced Encryption Standard (AES) Encryption and Mesh networking. Mesh networking allows the transceivers to jump over non-responsive nodes and take path of shortest network hops to deliver messages to the operators. A custom designed antenna is used to transmit and receive electromagnetic radiation from each of the sensor platforms completing the communications link. It consists of a horizontally polarized dipole that exhibits a 50-Ohm load in the ISM band and a short circuit at $60 \mathrm{~Hz}$ and elsewhere. The short circuit protects the highly sensitive front end of the radio from the high electric fields associated with operation at $500 \mathrm{kV}$. The antenna is located in a slightly conductive radome further protecting the antenna and cabling from the high electric fields.

Originally a 10-mW ISM band transceiver was designed into the sensor platform for use in remote electromagnetically quiet environments such as would be found in remote transmission line corridors. The Licensee, Lindsey Manufacturing, desired to extend deployment into city and urban environments requiring a much higher transmitter power output to overcome the high background noise levels. A one Watt transceiver was added under a Cooperative Research and Development Agreement (CRADA) between the INL and Lindsey. 


\subsection{Endpoint}

The endpoint performs a supporting role for the sensor platform in that it completes the link between the sensor platforms and the transmission line control room operators. Its function is to provide an information connection between the sensor platforms and existing communication infrastructure such as land line telephone, cell phone, Internet, or any other means available to deliver information to the operators. Together the sensor platforms and at least one endpoint make up the TLSM.

Originally the endpoint consisted of a custom buit10-mW ISM band transceiver and a universal serial RS-232 interface (see Figure 3). It supported two-way communications, communication protocol, packet encoding and decoding, and short-term energy storage (several minutes). It is intended to be located where information infrastructure exists such as at the power generating end or the load end, a substation. The RS-232 interface allows connectivity to almost any type of communication media. See Appendix A for a schematic of the original endpoint.

Since Lindsey Manufacturing desired to extend deployment into city and urban environments, a new higher power communications link was required that necessitated a new endpoint. The new endpoint is now provided by the communications link manufacturer and is not discussed here. Both endpoints work equally well in a remote electromagnetically quiet environment. The new endpoint is required for the urban environment. The endpoint does not require stationary deployment in a fixed location such as a generating station or a substation. It can be coupled to a laptop computer and used in a mobile mode when TLSM connectivity is required in the field, such as in a truck or in the air.

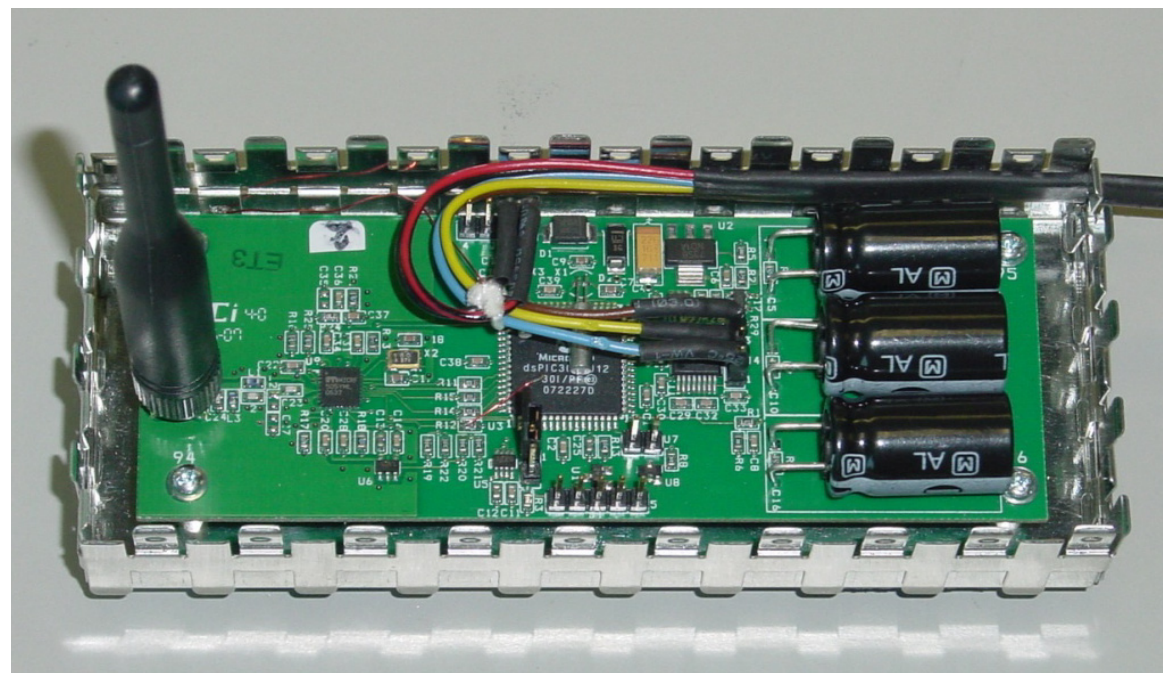

Figure 3. Endpoint electronics. 


\section{SYSTEM OPERATIONAL TEST}

SO testing took place over 2 years and at three different locations: Idaho Falls, Idaho; Azusa, California; and Buckeye, Arizona. Tests included operation on current carrying conductors, high energy vibration detection, IR (human body) detection, and communication range..

\subsection{Idaho Falls, Idaho}

The first deployment of the TLSM on an electrical power line took place during May 2009 (see Figure 4). Two sensor platforms were installed on a 14.4-kV distribution line in Idaho Falls, Idaho courtesy of Idaho Falls Power. They supplied two line men, a bucket truck, and a back up crew. The installation was performed in less than an hour. The platforms were periodically monitored during 2009. They were last visited and found to be operating during November of 2010. They are still in place today. This test deployed TLSMs on a conductor that passes enough current to power the monitors giving the system its first out out-of-doors long term test on a low voltage conductor. They operated through two summers and winters with temperatures ranging from about $100^{\circ} \mathrm{F}$ to $-20^{\circ} \mathrm{F}$. The installation did not have a permanently installed endpoint, so monitoring consisted of periodically loading endpoint equipment and a laptop computer into a vehicle and driving to the installation. Data was periodically collected and checked for validity.

Prior to installation on the distribution line in Idaho Falls, the $10-\mathrm{mW}$ radio link was tested in an electromagnetically quiet area for communication range. The sensor platform was located about $4 \mathrm{ft}$ above the ground on a small $(20 \mathrm{ft})$ rise. The endpoint and laptop was located in a vehicle.

Communication was monitored as the vehicle drove away from the rise. Reliable communication could be realized up to about 2 miles as long as line of sight was maintained. Two miles were better than expected and adequate for installations on remote transmission lines.

The Idaho Falls installation was located next to ( $200 \mathrm{ft})$ a very busy cell phone/radio communications tower, in the middle of Idaho Falls, and next a very busy thoroughfare. The ISM band ( 902 to $928 \mathrm{MHz}$ ) is located just above the cell phone Global System for Mobile Communication (GSM) downlink band ( 869 to $894 \mathrm{MHz}$ ). This means that the TLSM transmitter and receiver must compete with GSM band base station transmit power that spills into the ISM band. A GSM base station transmitter may transmit with a power level of tens of Watts. The end result is that the communication distance reduces from $\sim 2$ miles in an electromagnetically quiet environment to $\sim 1 / 2$ mile in an inner city environment. For this reason, the radio was upgraded from a10-mW transmitter to a $1-\mathrm{W}$ transmitter to accommodate installations in a typical large city urban environment as the licensee desired. During the same period the conductor clamping mechanism and power conversion electronics were also upgraded. 


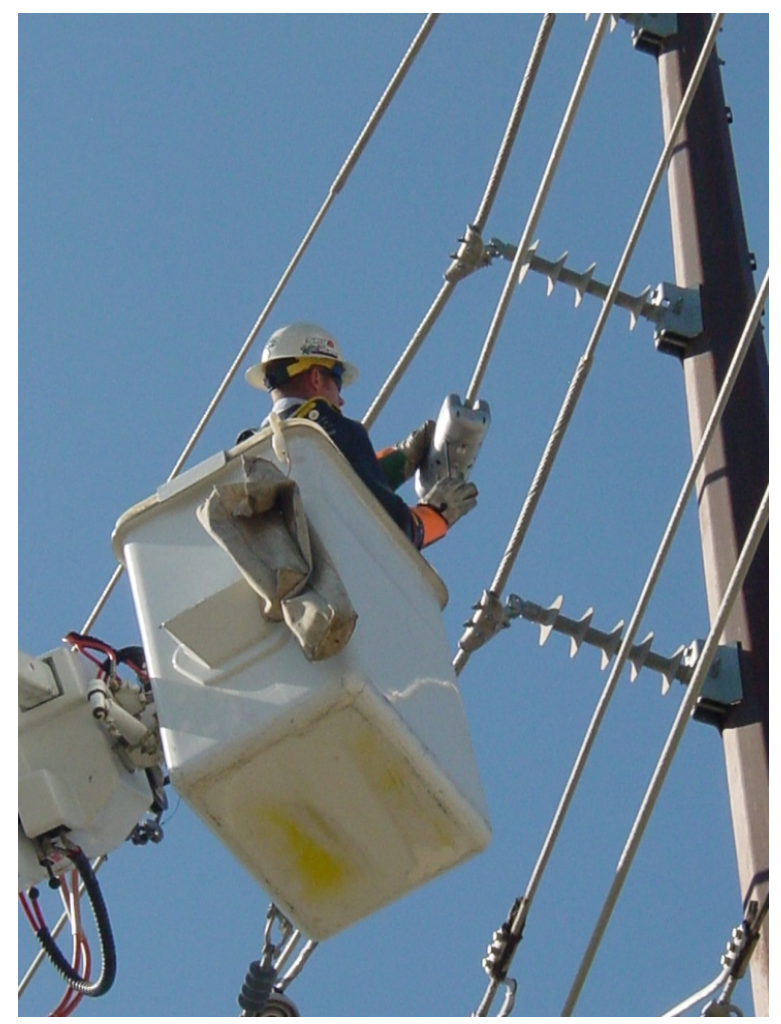

Figure 4. 12,470-V installation.

\subsection{Azusa, California}

During the period between May of 2009 and April of 2010 the INL entered into a CRADA with the Licensee, Lindsey Manufacturing of Azusa, California. The main focus of the CRADA was to upgrade the sensor platform radio and endpoint from $10 \mathrm{~mW}$ to 1 Watt, incorporate a ground to sensor platform distance measurement to augment the sag measurements based on conductor tilt, and incorporate the new communication protocol and sensor measurements into the existing engineering software. Meanwhile, Lindsey redesigned the conductor clamping mechanism and incorporated a corona-free radome around the radio antenna and clamping mechanism upper structure. Work was completed in April 2010 and three more were installed on a 14,400-V distribution line in Azusa, California (see Figure 5). The endpoint and a network data server were located at the Lindsey main office in Azusa where constant monitoring could take place. Unlike the Idaho Falls installation, real-time data was available to both Lindsey and INL over the Internet through a secure Virtual Private Network (VPN) connection.

The main purpose of the Azusa testing was to evaluate the new clamping mechanism, radio link, and software upgrades. The installation went very fast with the new one-bolt hot stick mounting requirement. The radio link performed to expectations, but as anticipated was limited to line of sight communications and the urban environment provided many obstructions. TLSM security functions such as movement of bodies at the base of a tower and vibration detection were not tested due to the urban location. The TLSMs were mounted over street intersections and above sidewalks. People, cars, and trucks were constantly passing underneath making it difficult to perform any meaningful security testing from an IR and vibration point view. These three units were monitored for 6 months and removed at about the same time the 4 units were installed in Buckeye, Arizona. After examination, evidence of standing rain water was found in the lower portion of the sensor platforms. This water was above the power conductors feeding the electronics compartments and severely corroded the power leads. As a result, new monitors incorporate weep holes to prevent the water from accumulating. The monitors installed in Buckeye do not 
have the weep holes. The water enters the monitor via the conductor that it is attached to. The conductor acts like a soaker hose and water drips off everywhere inside the monitor. The interior of the electronics compartment is isolated from the environment by design and did not show any evidence of water in the interior even though the power conductors were submerged.

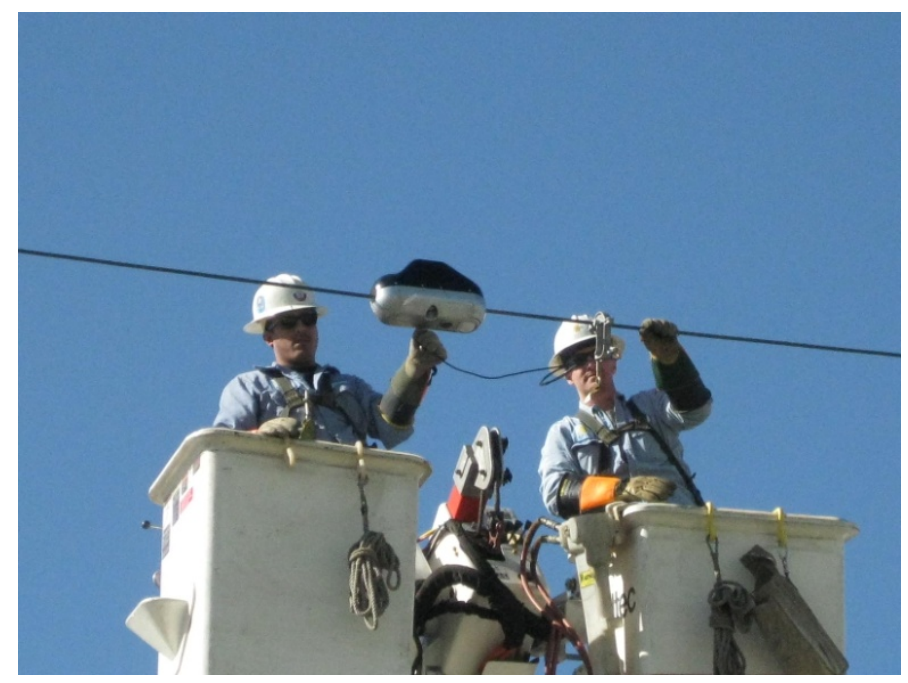

Figure 5. Azusa 4,600 V installation.

\subsection{Buckeye Arizona}

During the first week in October four more monitors were installed on the Westwing $500-\mathrm{kV}$ transmission line feeding Phoenix, Arizona from the Palo Verde nuclear reactor. The Westwing transmission line is currently the highest voltage line where the monitors are installed (see Figure 6). It is also located in a somewhat remote area that simulates the locations where the TLSM is intended to be deployed. The Salt River Project, one of Arizona's largest utilities, supplied a crew of linemen and a bucket truck capable of withstanding the $500-\mathrm{kV}$ line to ground potential for the installation.

An endpoint with a cellular telephone Internet link for remote Internet access was located at a local fire station in close proximity to the installation. The endpoint allowed for about 5 months of monitoring prior to traveling to Buckeye for testing in March. Figures 7 and 8 show typical data for the IR motion detection sensor and the vibration sensor over a 3-hour period. Both figures show events that were recorded during SO testing. Figures 9, 10, and 11 show the sum of the vibration spectra, electronics, conductor temperature, and a 2-D image of vibration over the 3-day period. Figures 7 through 11 show information that is relevant to security as well as transmission line operation. Several other measurements are also collected, but are not shown here. Note that in Figure 10 the conductor goes through an interesting twist and then relaxation of about 6 degrees every day at noon. 


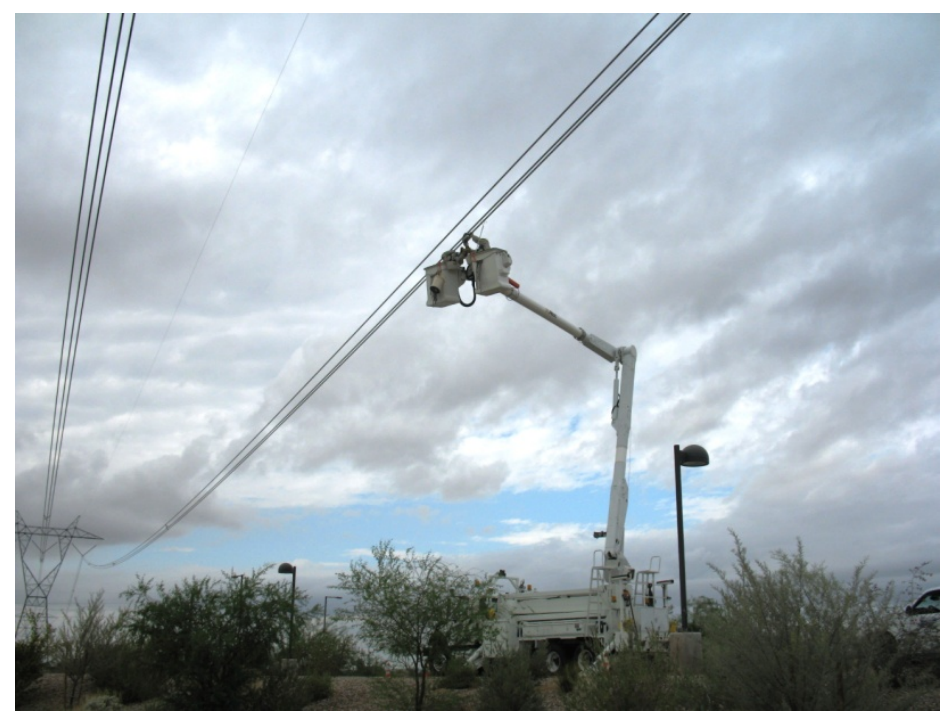

Figure 6. Buckeye 500-kV installation.

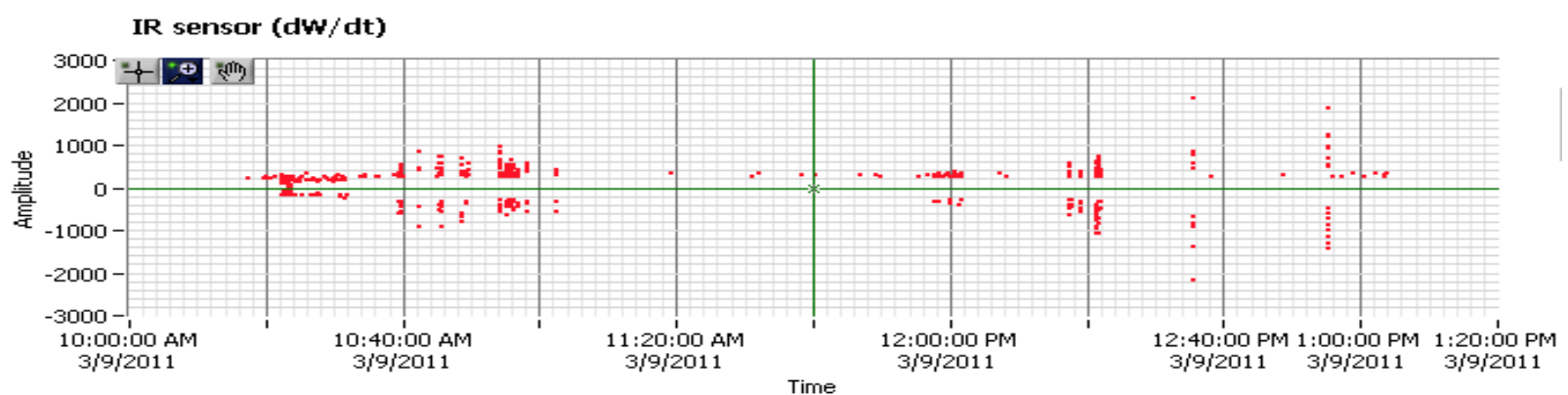

Figure 7. IR motion detection sensor.

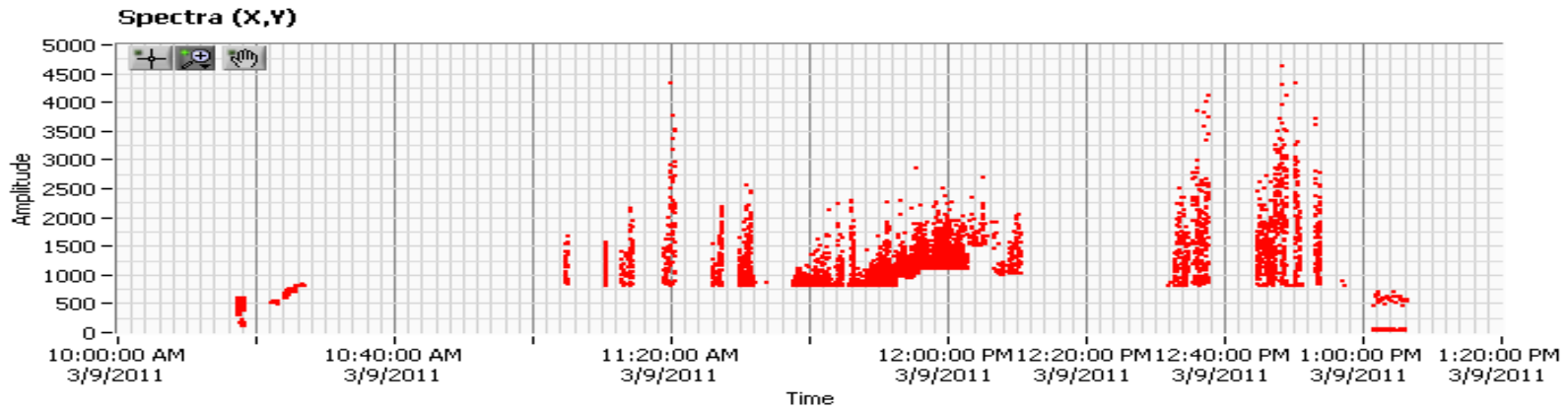

Figure 8. Vibration detection sensor. 


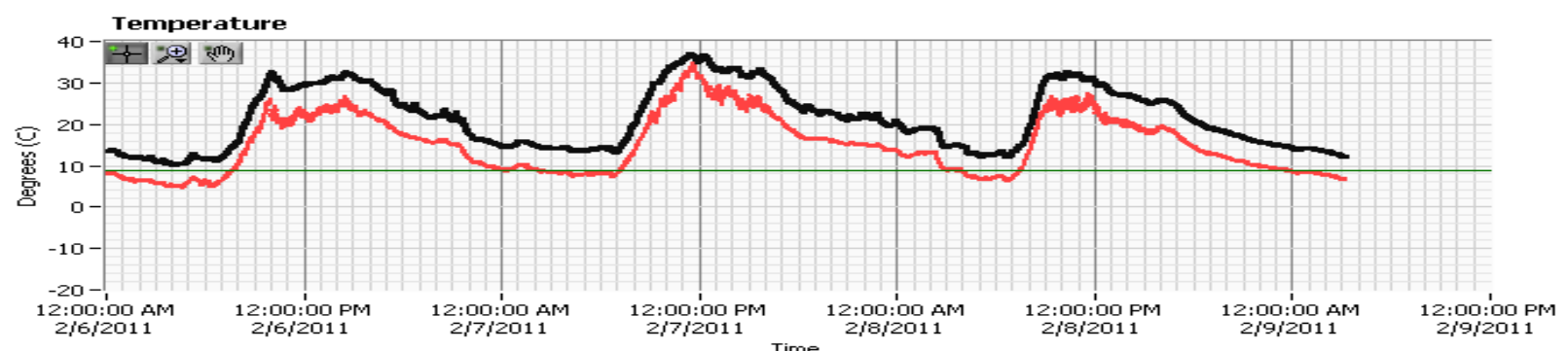

Figure 9. Electronics/conductor temperature.

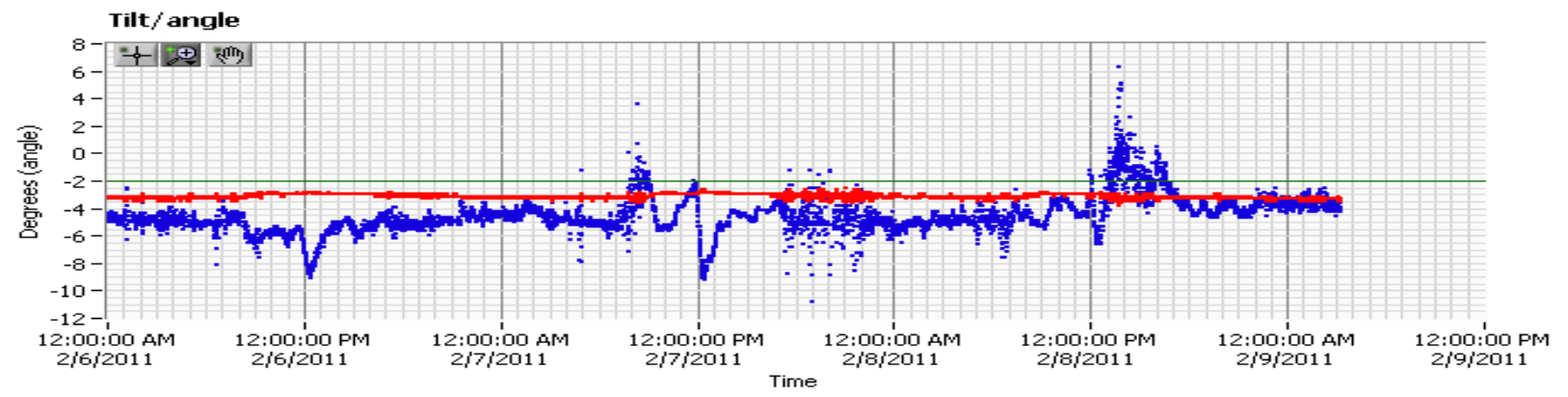

Figure 10. Conductor tilt and angle.

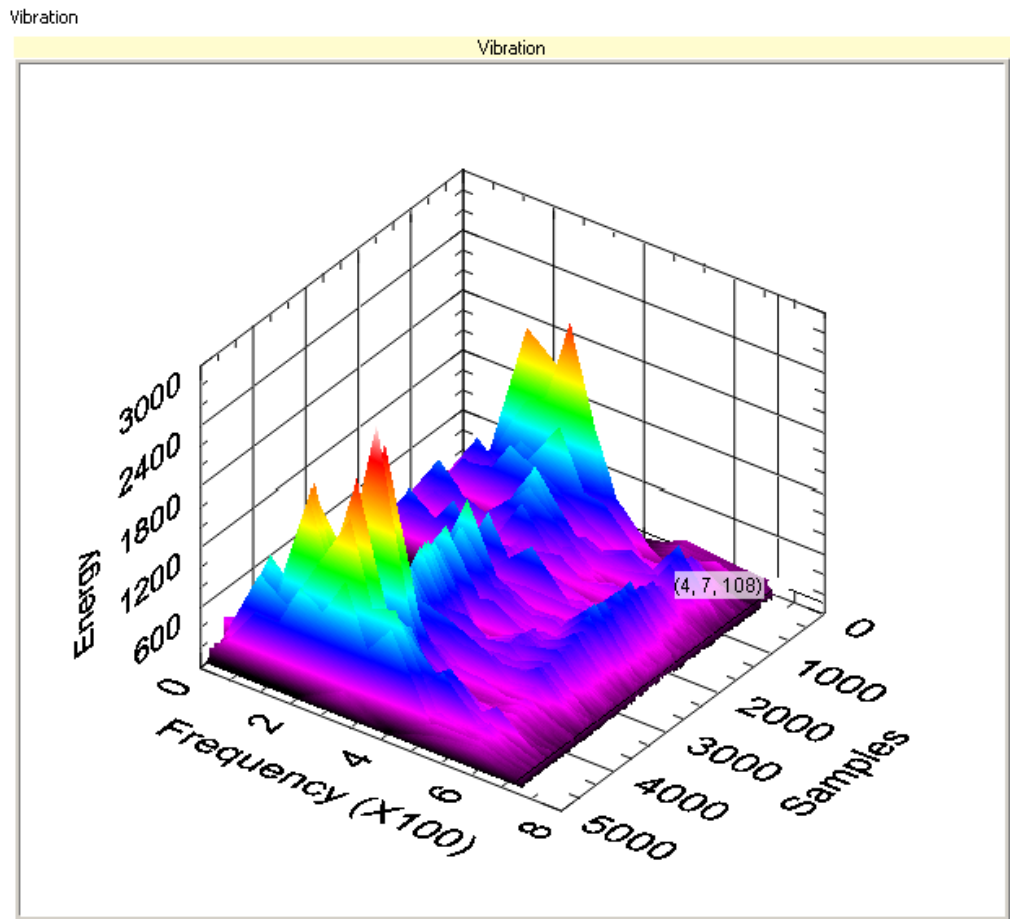

Figure 11. Vibration spectra.

Around February 16, 2011 three of the four monitors were still operating and data was recorded daily since October 2010. Shortly after, only sporadic communication was received from the three operating monitors. On March 9 we arrived at Buckeye and found that Monitor 5 was still operating but had been out of range of the endpoint due to the loss of two other monitors that were within network range of the endpoint. The fire men at the fire station informed us that a severe rain storm passed through about the 
same time we lost contact with the monitors. This is the only information we have that coupled with the findings with the Azusa platforms leads us to believe that rain water infiltration may have caused the problem. The Buckeye monitors did not have weep holes that would have allowed standing water to drain instead of accumulate. We will not know the failure mode until they are removed from service. Currently the monitors are still on the $500-\mathrm{kV}$ line.

The testing presented in the remainder of this section deals mainly with tests related to transmission line security. Included are vibration, IR movement detection, and communication test results.

\subsubsection{Vibration Tests}

Vibration tests are intended to determine the ability of the TLSM to detect high energy impacts related to tower unbolting. Previous attempts to unbolt towers resulted in the discovery of hammers and wrenches left at the scene of the unbolted tower. The hammers were used to impact the wrench to loosen the numerous bolts located at the base of tower's four legs. The Buckeye tests are designed to simulate this kind of activity and measure the TLSM response.

A mass weighing 3735 grams was attached to a $94-\mathrm{cm}$ cable. The cable was then attached to the tower structure such that a measured pull in centimeters back from the tower in the horizontal direction will impact the tower with a known impulse of energy. Two pull back distances of $50 \mathrm{~cm}$ and $70 \mathrm{~cm}$ were used during testing to simulate two impact energies of 5.3 and 11.4 Joules. Most tests impacted the tower legs at $100 \mathrm{~cm}$ above the concrete foundation (see Figure 12).

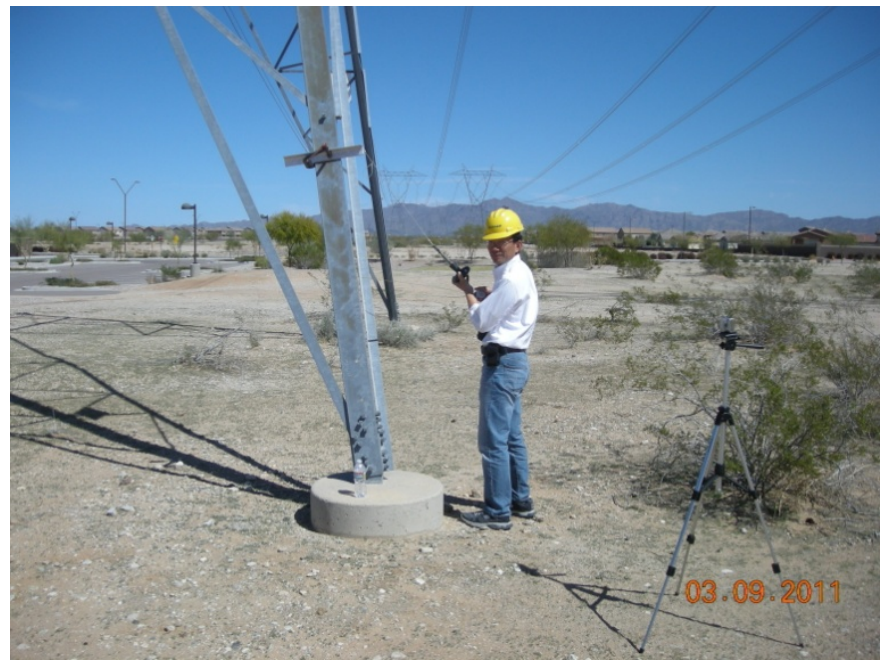

Figure 12. Impact testing at the base of each tower leg.

A few tests impacted the tower at 147 and $40 \mathrm{~cm}$ above the foundation to test for response variability due to impact height above the foundation. The 40-cm height corresponds to the tower mounting bolt location. Most figures showing the TLSM response as measured by the endpoint consist of three 70-cm pull back impacts and three 100-cm pull back impacts. All four legs were impacted on the two-angle iron faces that make up each leg resulting in eight data sets. The impacts were spaced about 15 seconds apart in time. Not all data sets are shown in this section, see Appendix C, "Tower Impact Testing Vibration Spectrum”.

The sensor platform was not located on the conductor at each tower as would be the case for a normal transmission line security application. Instead it was located midspan about 165 meters from the impacted tower. This location was chosen at the time of installation. The effect is that the vibrations originating at the base of the tower would now have to travel up the tower, through the cross arms, down the insulator, into the conductor, and then travel some 165 meters to the monitor. In effect, the location 165 meters 
from the impacted tower provides a greater challenge to the TLSM's ability to detect impact vibrations than if the TLSM was located on the conductor at the tower.

Figure 13 displays the vibration alarm message values that were sent from the sensor platform to the endpoint as the impact testing was taking place from 11:05 a.m. to 12:55 p.m. The X-axis is the time of day. The $\mathrm{Y}$-axis is the relative acceleration summed over all spectral bins for each event reported during an alarm. All 48 tower impacts to each of the four legs are displayed between 11:05 a.m. and 12:30 p.m. Between 12:30 a.m. and 12:55 a.m. miscellaneous impacts are displayed. Prior to 11:05 a.m. and after 12:55 p.m. background noise data was collected. Between 11:52 a.m. and 12:10 p.m. the background noise level increased requiring the alarm threshold to be increased from 750 to 1000 . At 12:30 p.m. the threshold was reduced back to 750 . Between 12:10 p.m. and 12:30 p.m. testing stopped when the local police department showed up unexpectedly. This required a 20 -minute impromptu explanation/presentation about what we were doing there and why we were banging on their towers.

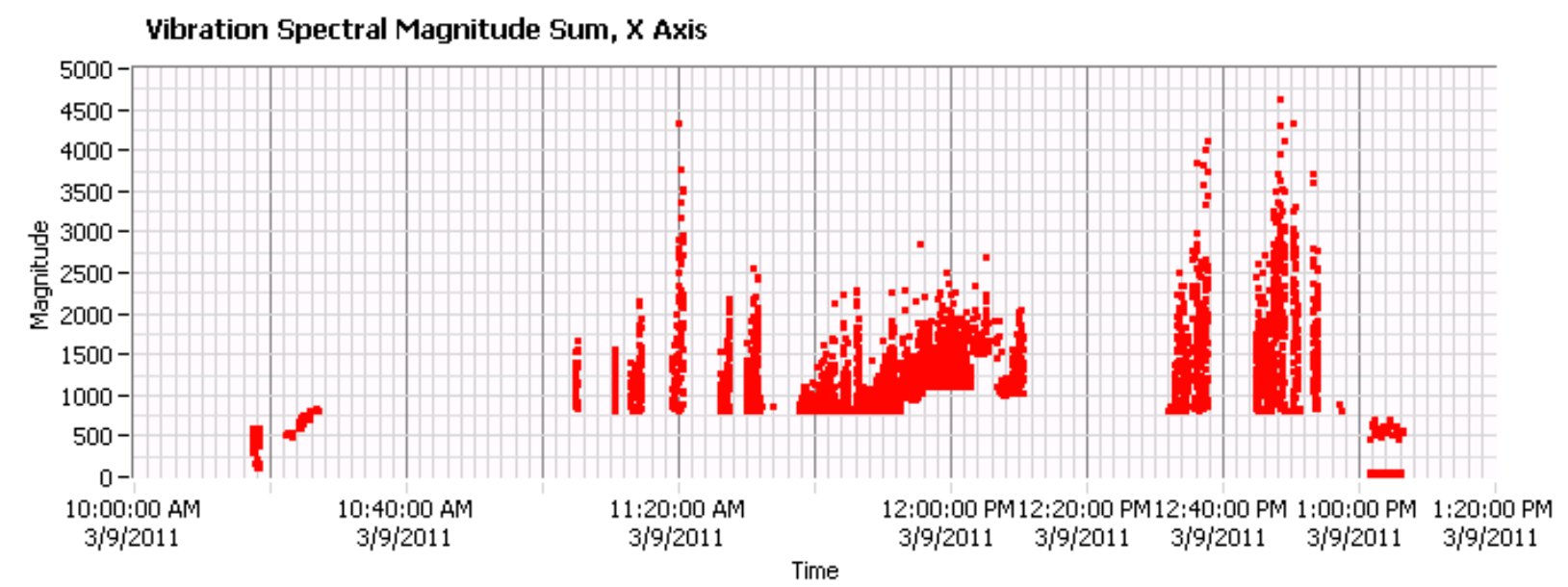

Figure 13. Impact test event results.

Figure 14 shows an expanded view of the 11:20 a.m. impact event. As can be seen, the event is really six events rolled into one. The three $50-\mathrm{cm}$ pull back impacts and the three $70-\mathrm{cm}$ pull back events are clearly defined and spaced about 15 seconds apart. Each event was reported to the endpoint about 10 to15 times during each event period.

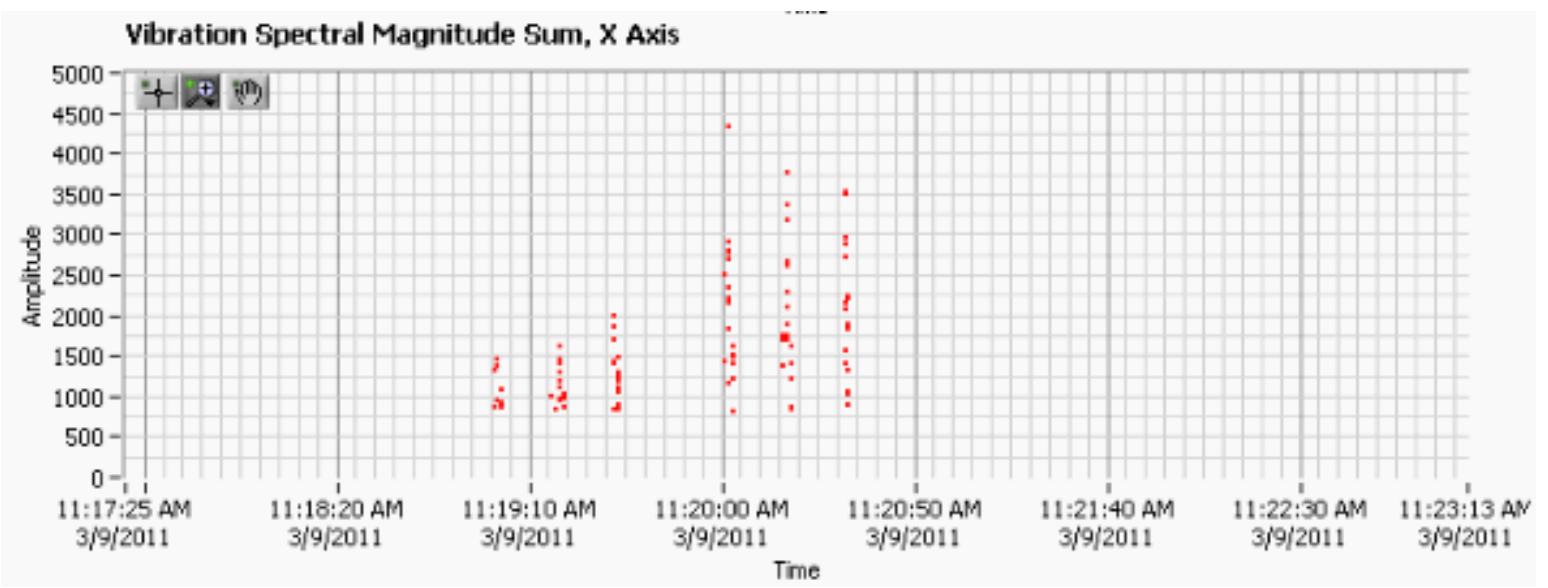

Figure 14. Expanded 11:20a.m. event.

Figures 15 to 20 consist of a 3-D plots representing the TLSM frequency spectral response to the impacts. The frequency spectrum shown in the plots represents a compressed spectral response as 
measured by the sensor platform. The sensor platform converts the time domain vibration signal to the frequency spectrum by the application of a 128-point FFT resulting in 64-discrete frequency bins. These 64 bins are then compressed into eight bins by sequentially summing eight spectral bins of the 64-point spectrum into 1 spectral bin of the eight. The reason for this is to reduce the communication bandwidth required to transmit a spectral representation at the expense of the spectral resolution.

The transmission line runs basically from the south to the north. The four legs are labeled southwest, northwest, northeast, and southeast. Each leg is made of angle iron with two faces. The southwest leg has a south and a west face that was impacted. The northwest leg has a west and a north face that was impacted and so on for the northeast and southeast legs.

Figures 15 and 16 show the spectral response from the impacts to the southwest leg of the tower. This leg is closest to the conductor where the sensor platform is mounted. Figure 15 shows the response when impacts are presented to the west face. Figure 16 shows the response when impacts are presented to the south face of the same leg. The three $50-\mathrm{cm}$ and three $70-\mathrm{cm}$ impacts can be clearly identified by their amplitude and location. First, the three 50 -cm impacts located between 0 and 30 samples. Second, the three $70-\mathrm{cm}$ impacts located between 30 and 70 samples. A total of 70 to 90 spectral responses were reported to the endpoint for these six events.

Figures 17 and 18 show the spectral response from the impacts to the northeast leg of the tower. This leg is furthest from the conductor where the sensor platform is mounted. Figure 17 shows the response when impacts are presented to the north face. Figure 18 shows the response when impacts are presented to the East face of the same leg. Differentiating between the 50 and $70-\mathrm{cm}$ impacts is more difficult on this leg, but the impacts are clearly present. A total of 250 spectral responses were reported to the endpoint for these six events.

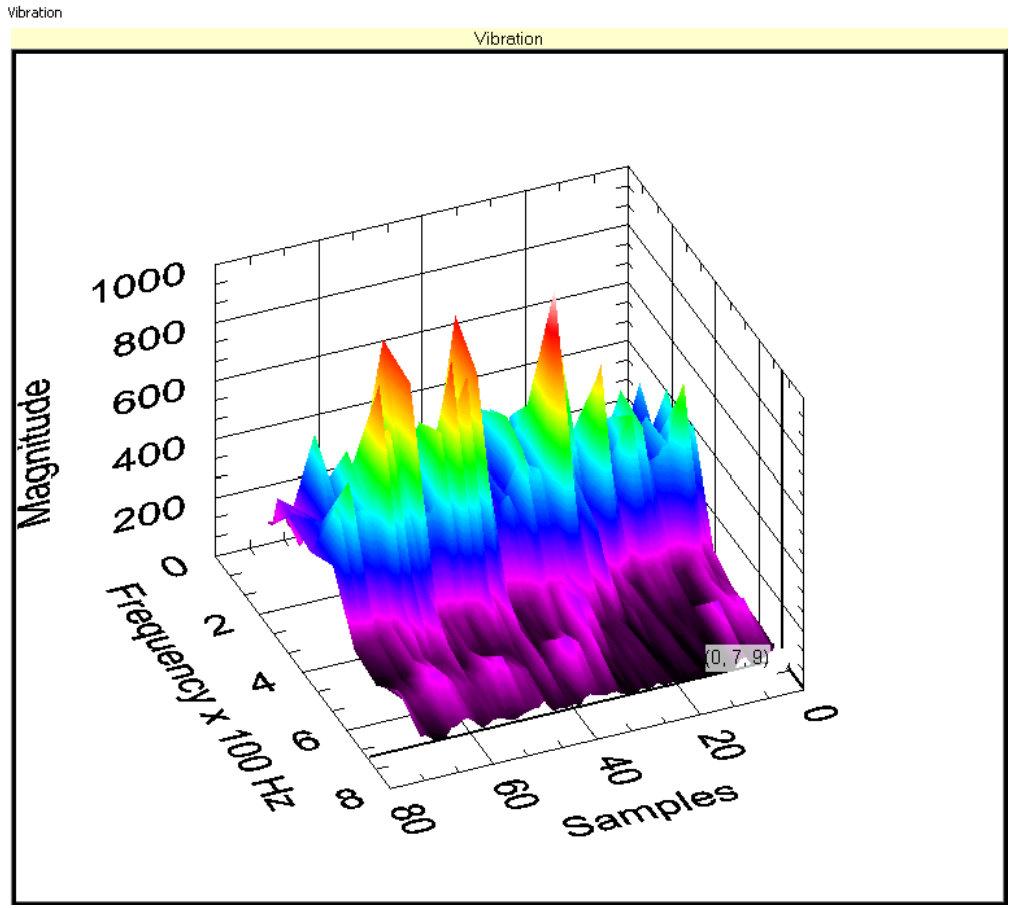

Figure 15. Southwest leg, west face, 1-meter elevation, 5.3 to 11.4 joule impulse. 


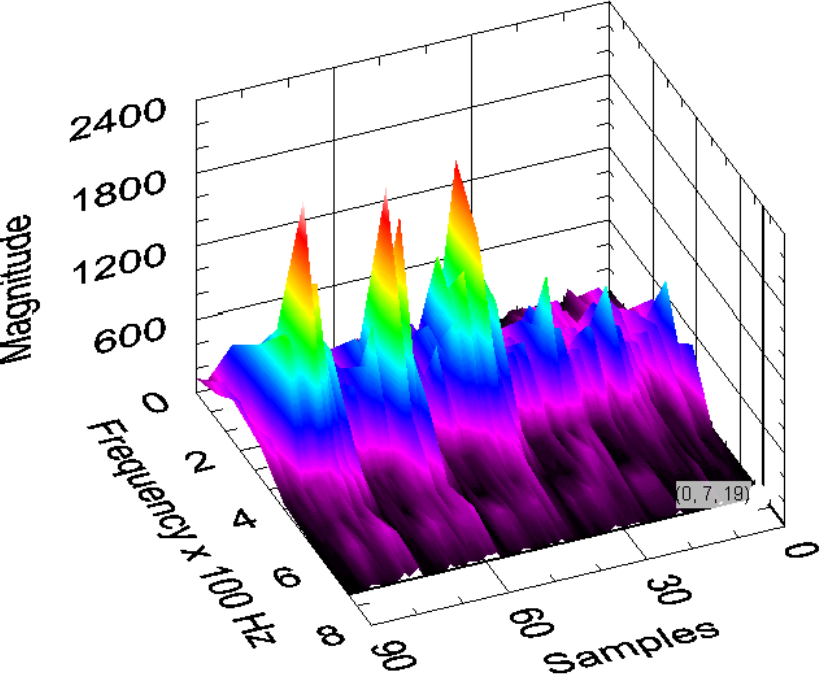

Figure 16. Southwest leg, south face, 1-meter elevation, 5.3 to 11.4 joule impulse.

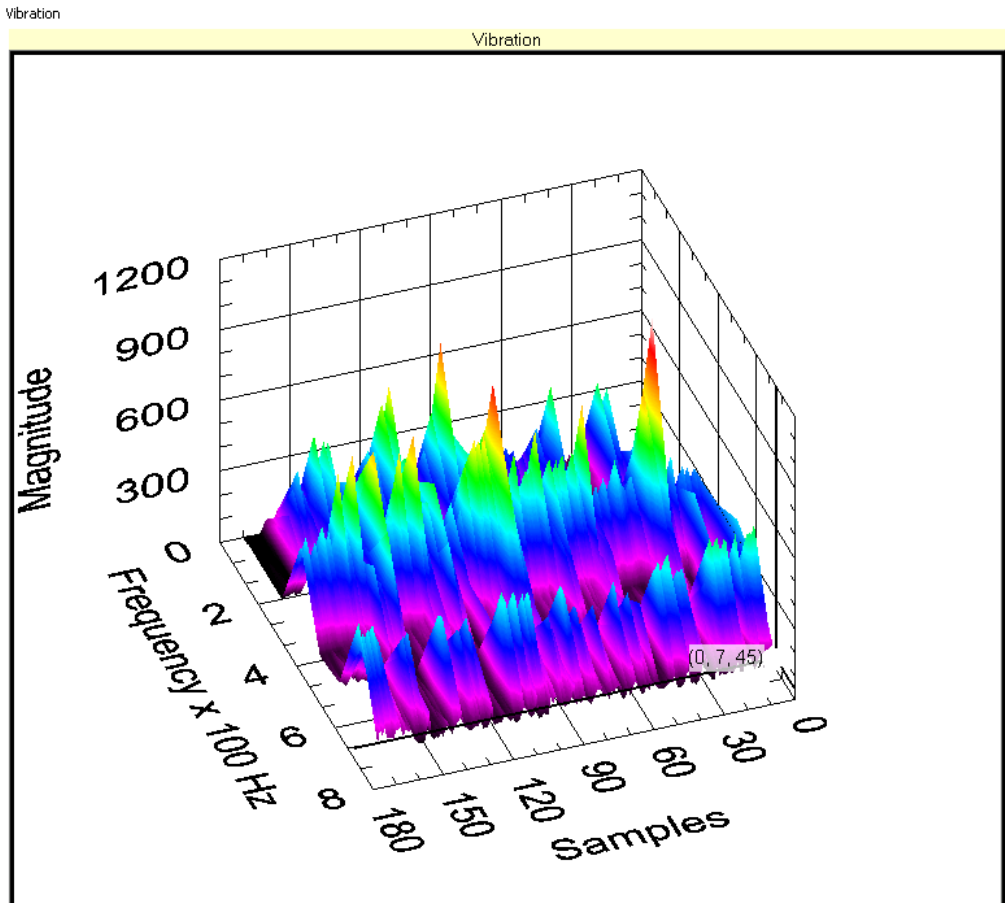

Figure 17. Northeast leg, north face, 1 meter, 5.3 to 11.4 joule impulse. 


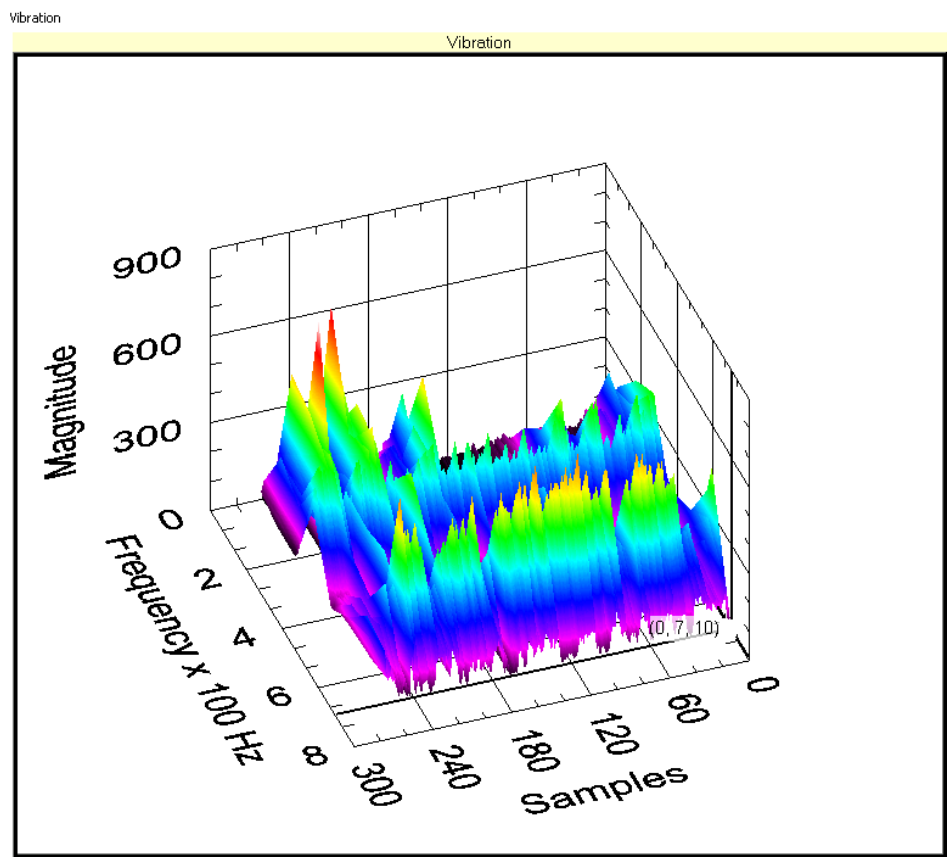

Figure 18. Northeast leg, east face, 1 meter, 5.3 to 11.4 joule impulse.

Figures 19 and 20 show the spectral response from more impact testing to the southeast leg of the tower. The test results for this leg were previously displayed in Figures 15 and 16. Figure 19 shows the response when impacts are presented to the west face at the 1.47-meter level. Figure 20 shows the response when impacts are presented to the same leg at the 0.4-meter level that is the level of the mounting bolts (see Figure 21). Differentiating between the 50 and $70-\mathrm{cm}$ impacts is fairly clear on this leg. The impact response amplitude may have increased above those impacts previously measured. A total of 680 spectral responses were reported for these events.

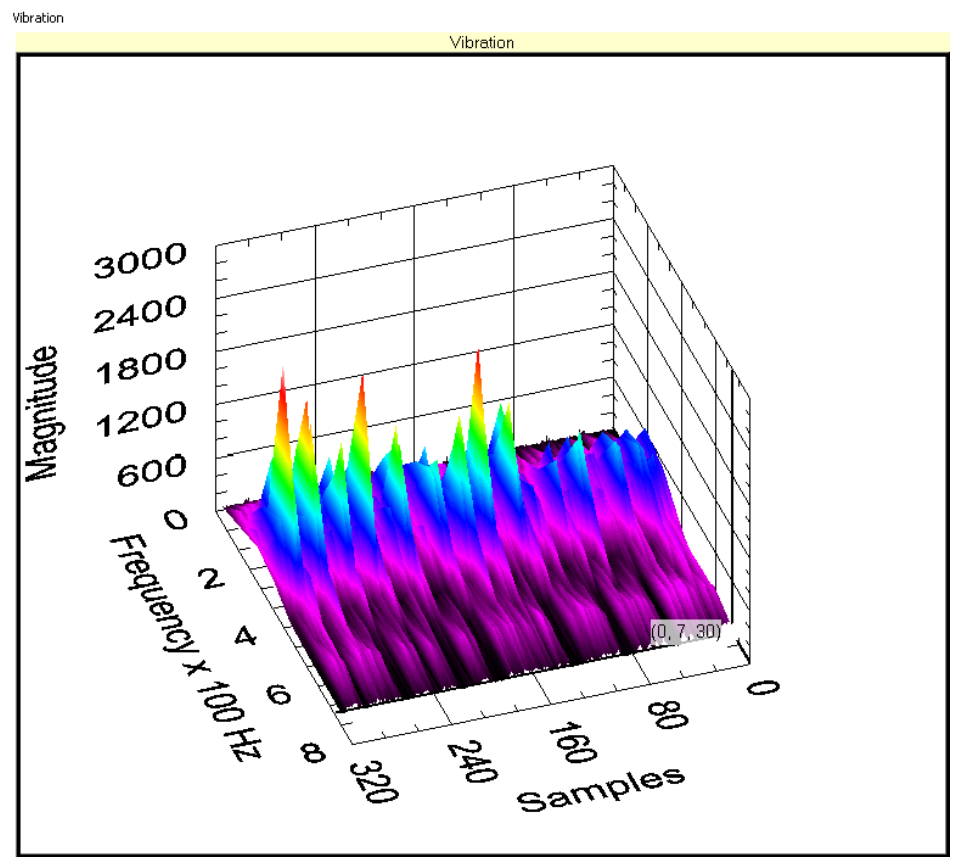

Figure 19. Southwest leg, west face, 1.47 meter, 5.3 to 11.4 joule impulse repeat. 


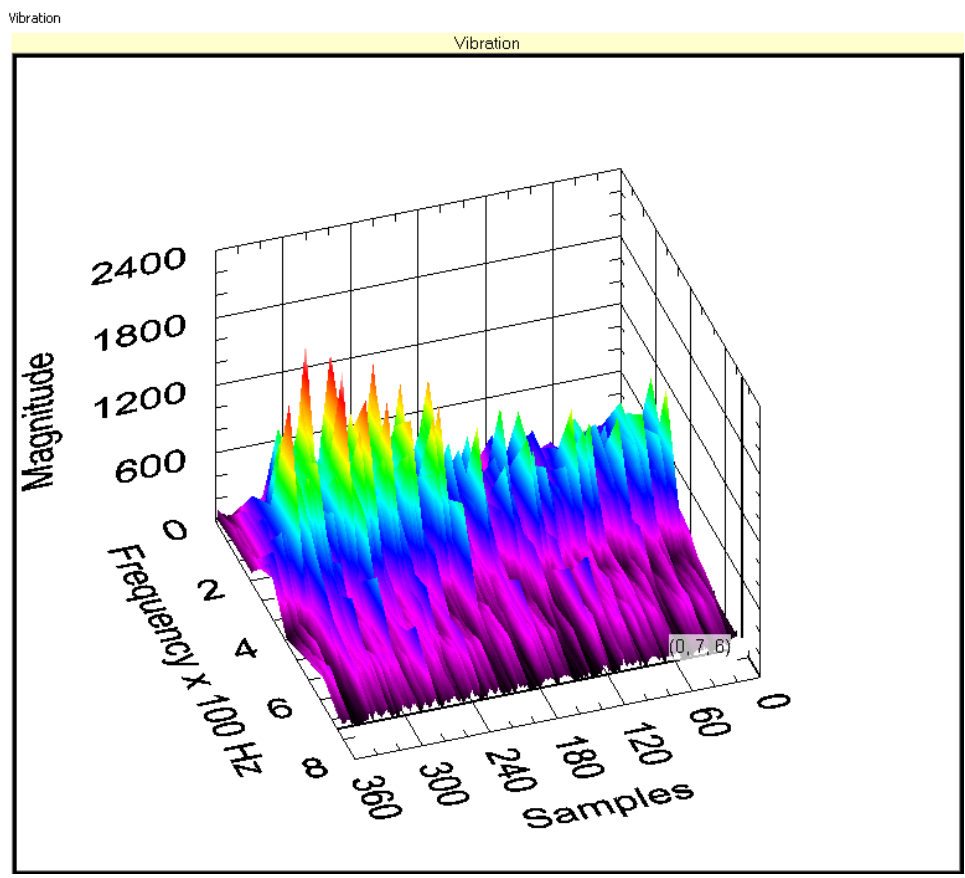

Figure 20. Southwest leg, west face, 0.4 meter, 5.3 to 11.4 joule impulse repeat.

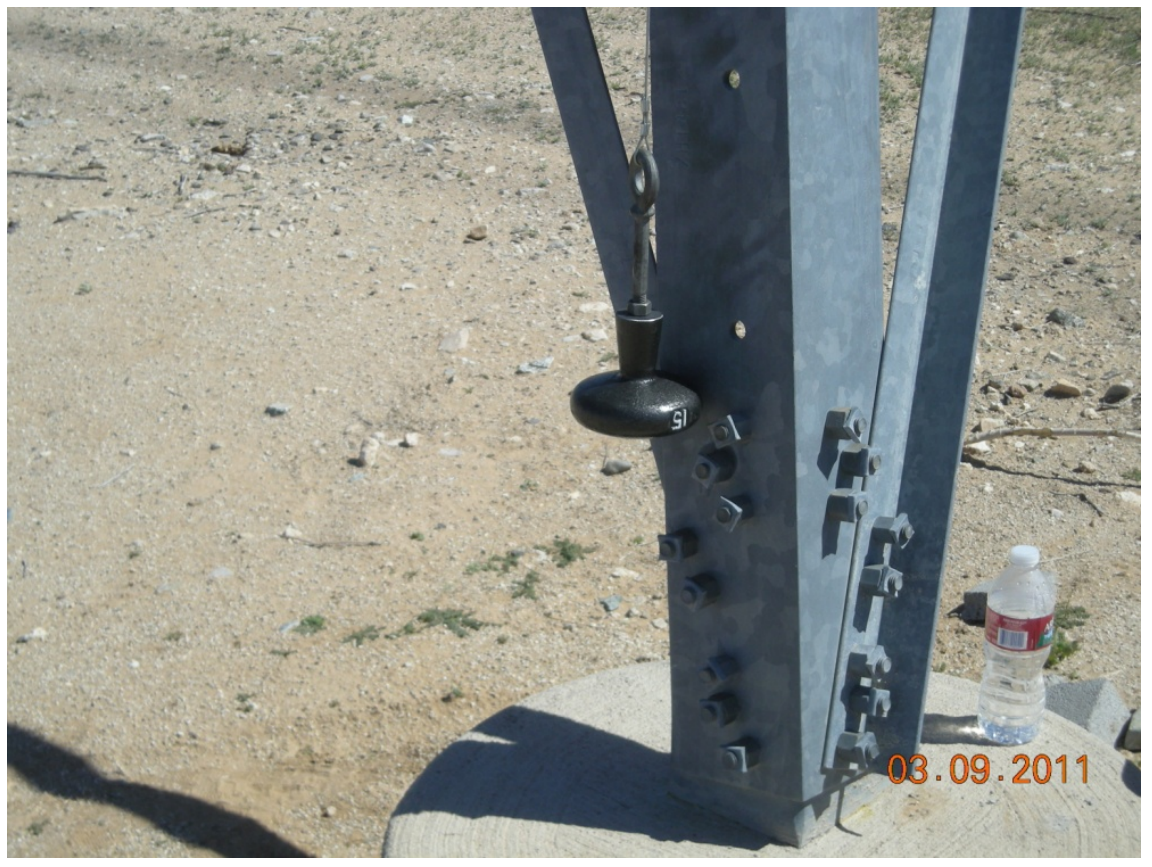

Figure 21. Southwest leg, west face, 0.4 meter (bolt level), 5.3 to 11.4 joule impulse repeat.

\subsubsection{IR Motion Detection Tests}

Non-natural high energy impacts to a tower coupled with indications of a warm body moving at the base of a tower are the prime indications used by the TLSM to differentiate between natural occurring events and events related to transmission line tampering. Each measurement alone is not enough to determine tampering. Coupling both together increases the probability of tampering detection. 
The IR motion detection tests presented are intended to determine the ability of the TLSM to detect the movement of warm bodies (people) at the base of the tower. Motion detection tests were simply accomplished by periodically moving around underneath the sensor platform while recording activities. Two figures present the results. Figure 22 displays sensor activity during the morning vibration testing and Figure 23 records the afternoon activities. Both data sets were recorded on a cloudless bright sunny day.

Figure 22 IR event description:

A. The equipment was set up in the parking lot and data recording was started. IR detection thresholds were measured and set just above the noise level.

B. One person made several trips to and walked underneath the sensor platform.

C. Next, two people are now at moving around underneath the sensor platform.

D. Vibration testing started.

E. False alarms due to IR threshold set too close to noise level.

F. Unknown event.

G. Police arrive and were given a short demonstration.

H. Vibration testing ends.

I. Car parked under sensor platform while attempting to measure conductor temperature with hand-held IR temperature sensor prior to breaking for lunch.

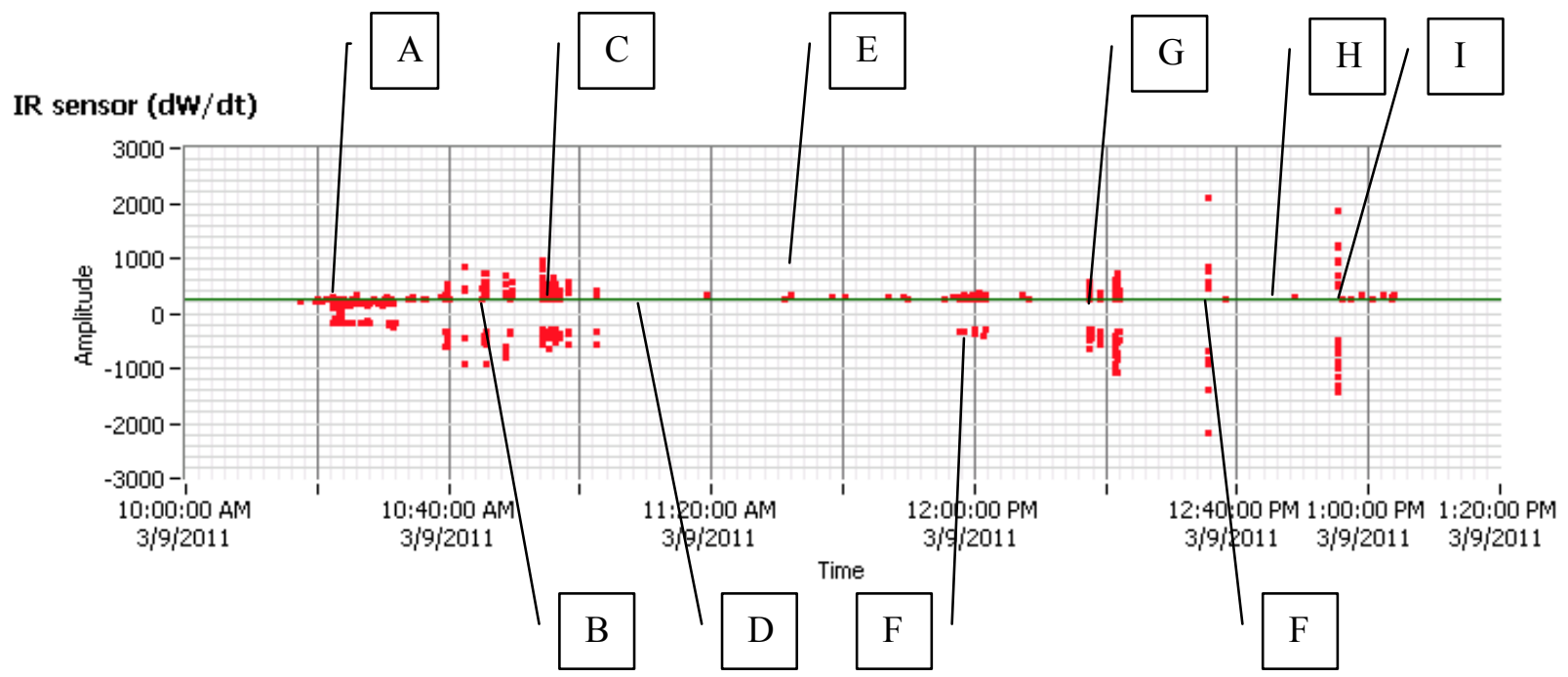

Figure 22. Morning IR sensor.

Figure 23 IR event description:

A. The equipment was set up in the vehicle and data recording was started. IR detection thresholds were measured and set just above the noise level.

B. Person under sensor trying to measure conductor temperature with a hand-held IR temperature sensor prior to starting radio communications distance test. 
C. Conducted distance testing from B to D. These are unknown events that occurred while conducting the distance test. We were not in the area so we do not know what took place. There were people in the area.

D. Person back under the sensor trying to measure conductor height and testing ground to sensor platform distance sensor.

E. Unpacking and repacking vehicle.

F. Finally made a good ground to sensor platform distance measurement of $36.7 \mathrm{ft}$ was made when sunlight subsided and the laser pointing device was now visible. We then drove off to complete the distance testing.

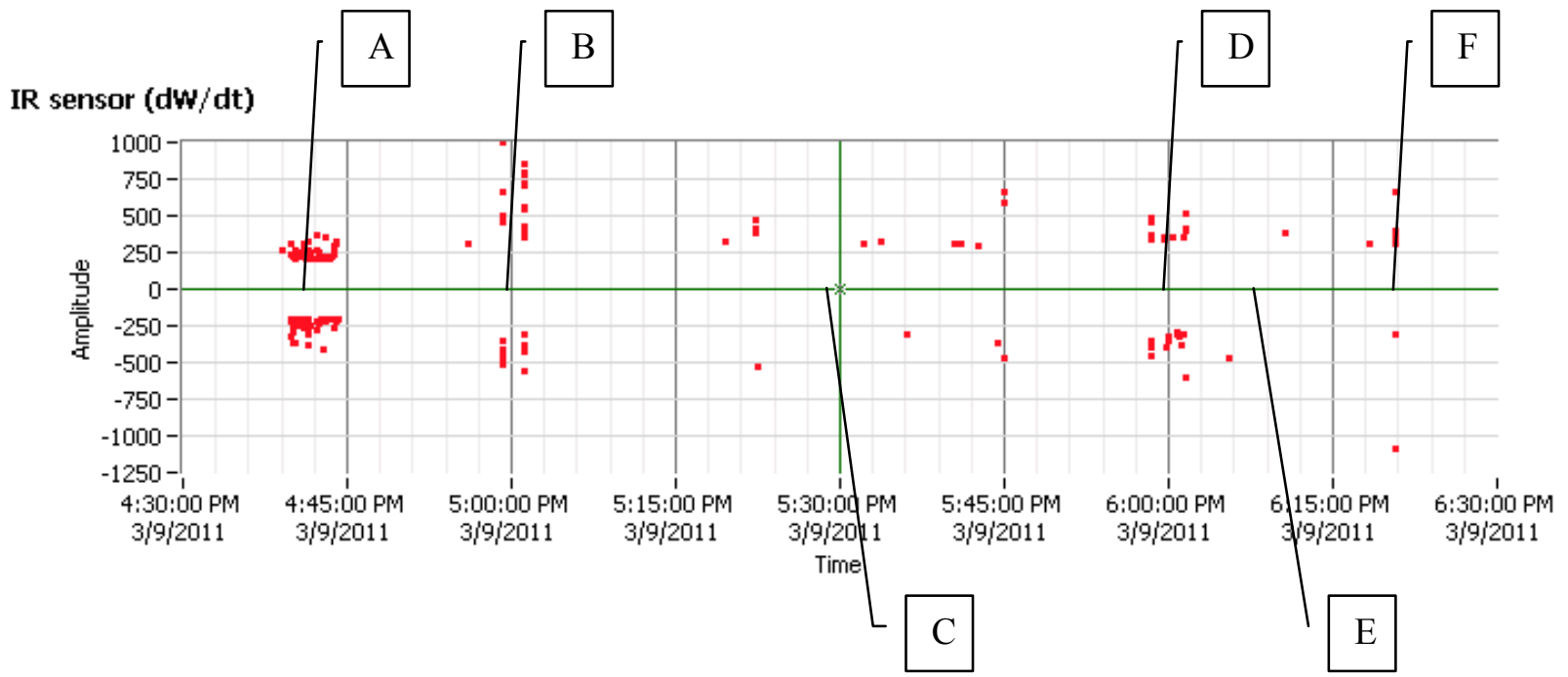

Figure 23. Afternoon IR sensor activity.

\subsubsection{Radio Communication Distance Test}

The last test conducted at Buckeye was a radio communications range test. Previous range testing with the 10-mW transmitter in an electromagnetic quiet site indicated two-way communication distances up to 2 miles line of site were possible. These tests were conducted with the platform mounted about $5 \mathrm{ft}$ above the ground. This distance was very encouraging when considering the distance should increase when the sensor platforms are mounted high in the air on a transmission line. Moving the TLSM into an urban environment reduced that range to about $1 / 2$ mile. This range reduction would only allow the sensor platforms to hop over 1 defective sensor platform when considering that the towers are typically spaced about 1/4-mile apart. The urban range reduction prompted Lindsey Manufacturing to request a radio upgrade from 10-mW to 1-Watt transmit power to allow operation in an urban environment.

Prior to Buckeye, a range test of the new 1-Watt transmitter was performed in Idaho. This test also incorporated a new sensor platform antenna. It also was performed in an electromagnetic quiet environment. The sensor platform was fixed on the side of a slight hill elevating it to about $50 \mathrm{ft}$ in the air relative to the endpoint that was mounted in a vehicle. Reliable communication was achieved up to about 2.5 miles line of sight. Beyond the 2.5 miles line of sight was lost due to hills.

The Buckeye range testing involved a mobile endpoint located in a vehicle and 1 sensor platform deployed about $37 \mathrm{ft}$ in the air on the transmission line conductor. All previous Idaho range tests did not have a sensor platform located on a transmission line. The vehicle drove on the right-of-way road in between the two transmission lines. First we drove north and then south. Communication was lost at about 3/4 mile from the sensor platform when the endpoint was located right next to a busy cell phone tower when traveling the north. Communication was not established as we continued moving north 
putting several miles between the cell tower and the mobile endpoint. Next, the vehicle moved from the sensor platform to the south. Reliable communication continued up to the point where the vehicle was stopped by a desert wash at 2.5 miles preventing the vehicle from moving any further South, Reference Figure 24. At this point we turned back, went around the wash, and returned under the transmission line at 2.75 miles where communication was re-established. Next, we traveled to the West where we again reestablished communication at 4.5 miles. At this point we were not under the transmission line but were elevated about 25 feet above the ground on a freeway overpass. This testing did not establish the maximum reliable communication distance, but did prove that reliable communication could be attained up to 4.5 miles.

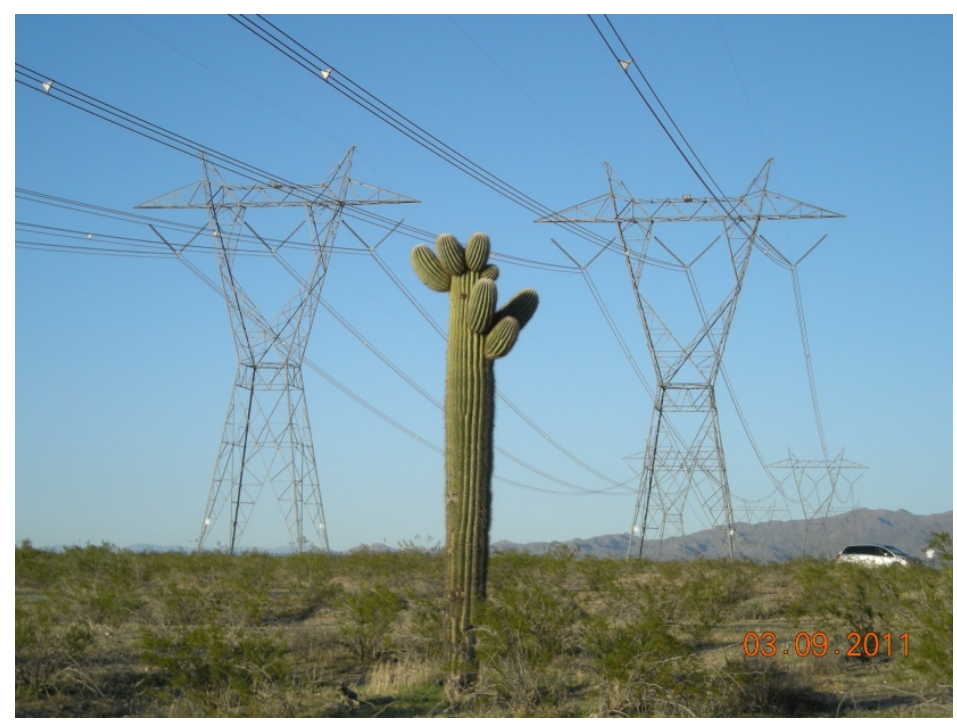

Figure 24. Under the transmission line at 2.5 miles. 


\section{CONCLUSIONS}

A sensor platform and communications mechanism capable of monitoring electrical power transmission line security and operational characteristics was developed by the INL and Lindsey Manufacturing. Final development and operational testing was funded by TSWG to support commercialization of technologies capable of combating terrorism. Reported in this document is a description of the system design and operational test results.

Operational tests challenged the system's ability to detect the presence of warm bodies (humans) at the base of the tower, detect high energy impacts related to malicious acts such as tower unbolting, and report the information over long distances where communication infrastructure does not exist. An IR sensor was employed to detect the movement of warm bodies. The sensor was challenged by people and vehicles moving under the sensor. The system successfully time tagged, displayed, and recorded these events over the course of a day. Accelerometers were employed to detect high energy impacts due to tower tampering and other acts of sabotage. These sensors were challenged by introducing a series of mechanical impacts to the base of the towers. The impact events and a compressed frequency spectrum for each event were also successfully time tagged, displayed, and recorded. The communications radio was upgraded to allow reliable operation in the electromagnetically noisy urban environment. The range was increased to about 1 mile in the vicinity of interfering cellular telephone towers and about 4.5 miles in a quiet environment allowing the mesh network to reform network routes over several inoperable tower sensor platforms.

Deployment on transmission lines in three western US states challenged the electronics and cable clamping mechanisms from an installation and environmental aspect. The platforms survived rain, snow, and ambient temperature extremes ranging from $-20^{\circ} \mathrm{F}$ to above $100^{\circ} \mathrm{F}$. Water infiltration was an issue and has been addressed.

The transmission line security monitor provides security and operational functions to electrical transmission line operators. These functions help provide reliable electrical power to industry, the military, and the populous. Essentially it is a generic sensor platform capable of: deployment on electrical transmission lines up to $500 \mathrm{kV}$, providing communications where communication infrastructure does not exist, extracting operating power from the transmission lines, and interfacing to any number of sensors required to support a mission. 
Appendix A Schematics 


\section{Appendix A}

\section{Schematics}

The schematics presented in Appendix A represent TLSM schematics for the sensor platform and the endpoint respectively. These represent the original design for TSWG using a $10 \mathrm{~mW}$ transceiver. Lindsey Manufacturing of Azusa, CA licensed the technology and extended the desired to extend deployment into the urban environment. Lindsey entered into a Cooperative Research and Development Agreement (CRADA) with the INL to increase transmitter power and add other transmission line related operational features. Thus, these two schematics are presented for reference purposes only. Any questions or inquires related to the design of the TLSM referenced in this report should be directed to Lindsey Manufacturing, P.O. Box 877 North Georgia Ave., Azusa, CA, 91702.

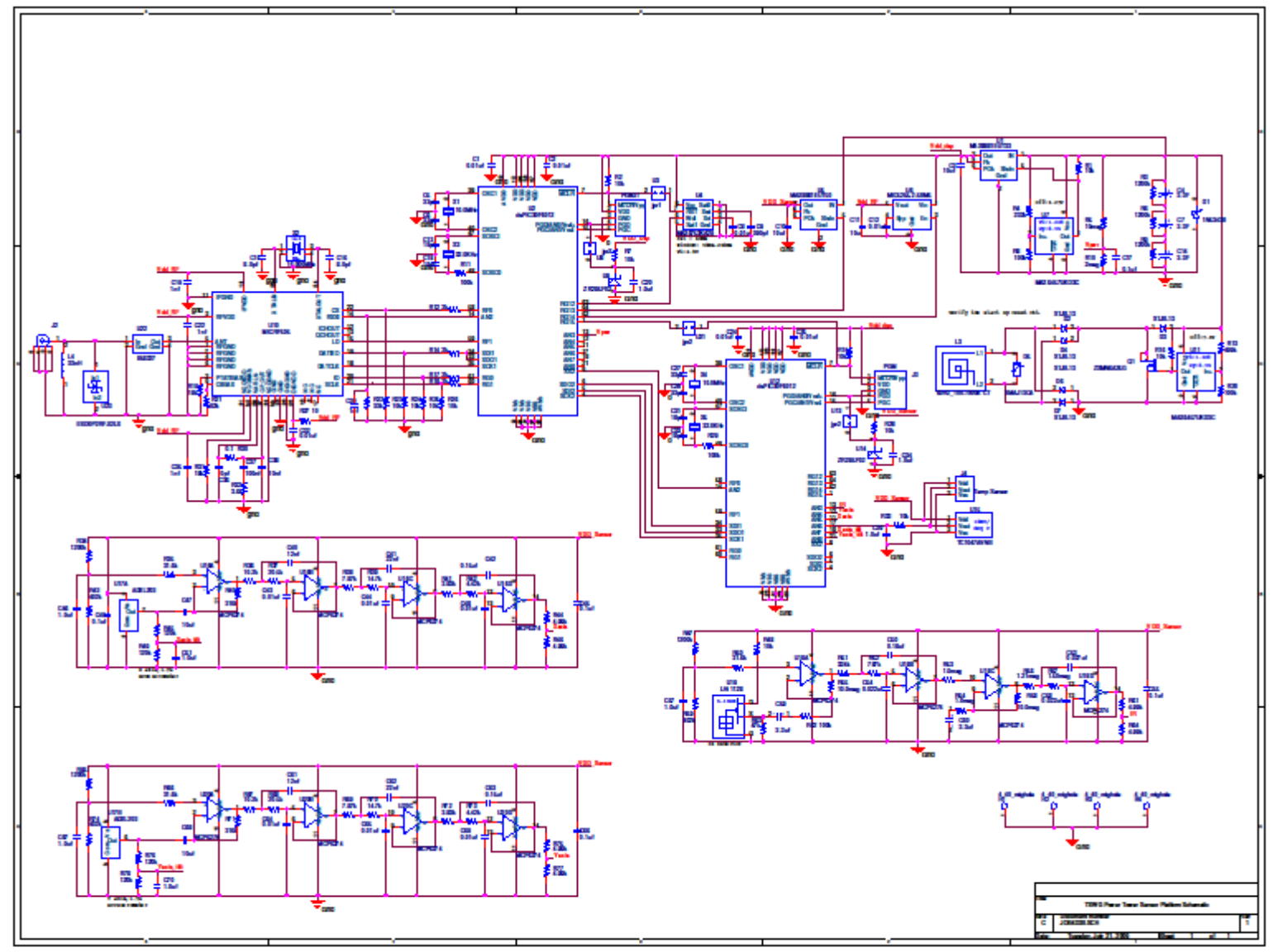

Figure A-1. Sensor platform schematic. 


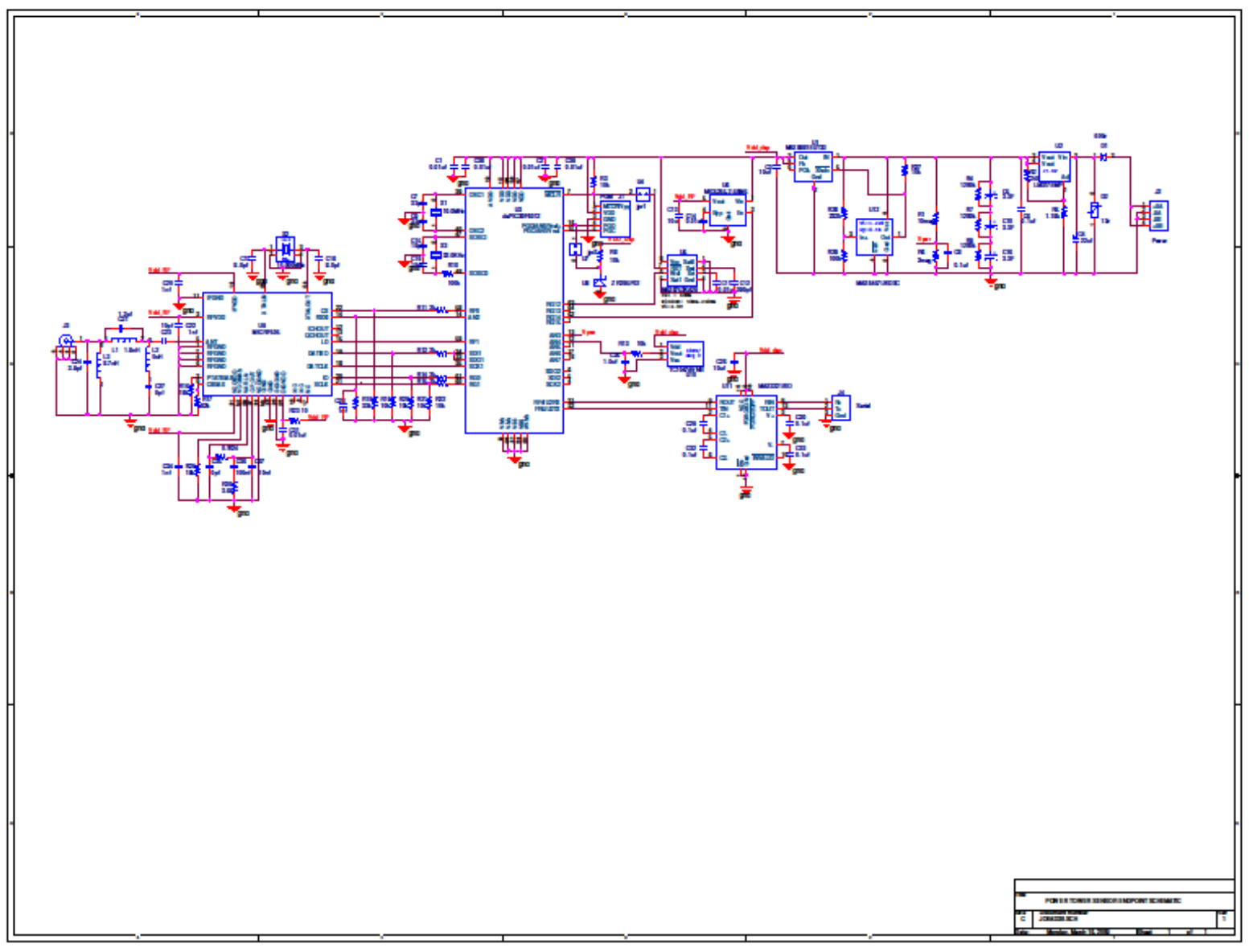

Figure A-2. Endpoint schematic. 
Appendix B

\section{Engineering Application}




\section{Appendix B}

\section{Engineering Application}

A Labview TM application was created that provides an engineering interface for monitoring the performance of up to three sensor platforms on a transmission line installation that could consist of hundreds of platforms. This application is not intended to perform an "operator's interface" function. It does provide the necessary information that will allow a utility to integrate Transmission Line Security functions into their daily operating software applications.

The application runs on a standard PC and has four display tabs: (1) Operate, (2) Statistics, (3) Setup, and (4) Spar Canyon.

The Operate Tab (Figure B-1) displays sensor information in a time tagged vs. sensor output Y vs. X graph format. Information displayed includes: (a) The IR sensor detection circuit time derivative. (b) The vibration Power for both the $\mathrm{X}$ and $\mathrm{Y}$ axis accelerometers. (c) The ultra sonic distance sensor output. (d) The board and conductor temperature. (e) The conductor tilt and angle. (f) The received message identification number and time since that message was last received. In addition, the on board storage capacitor voltage and received message signal strength is also displayed.

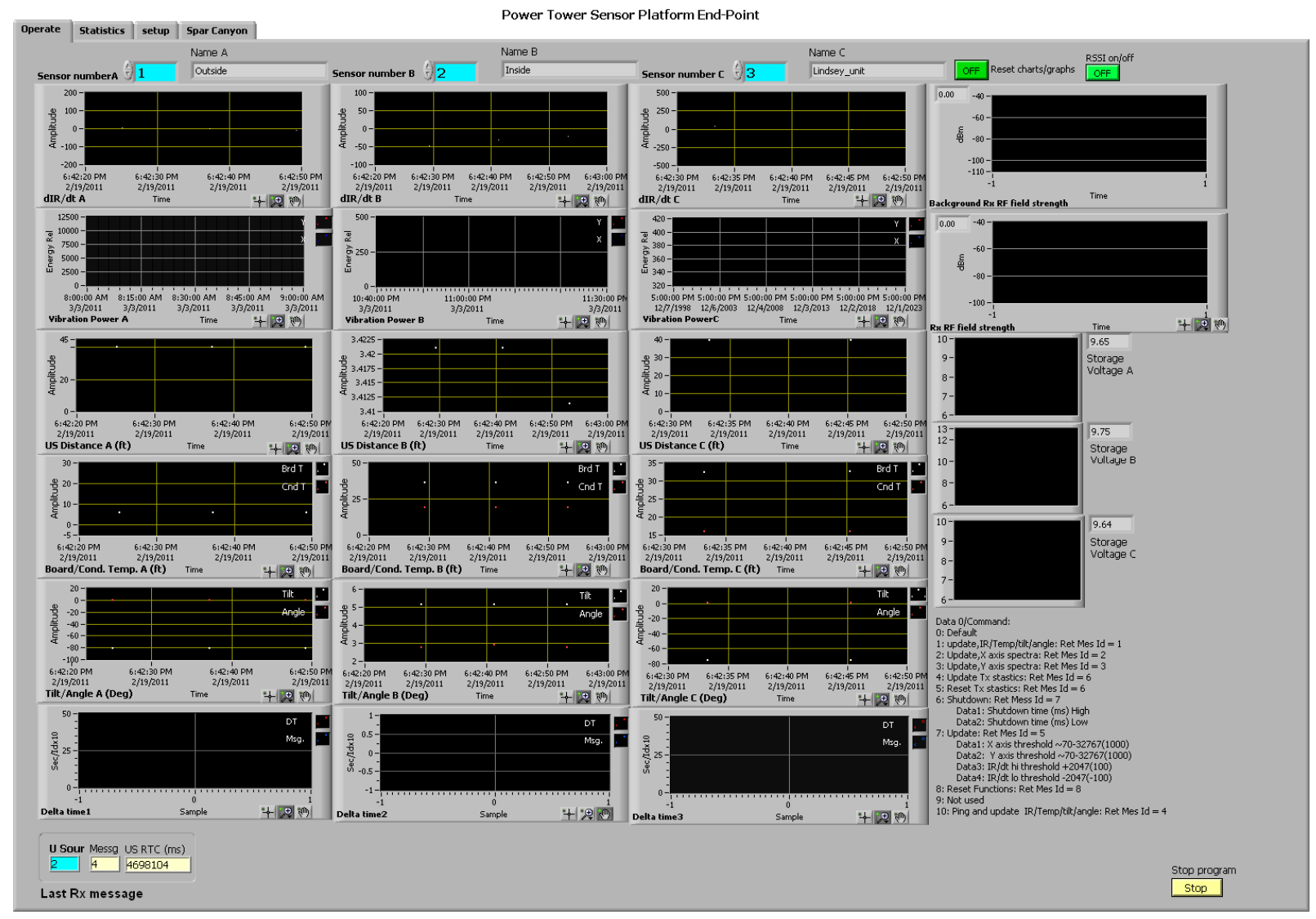

Figure B-1. Operate tab. 
The Statics tab (Figure B-2) displays miscellaneous information useful when determining system performance. Information displayed includes: (a) the number of ping and updates sent vs the number of ping and update responses. These two numbers should be equal when the network is performing at its optimum. (b) The time when a transmission was sent to a sensor platform and the time when a response to the transmission was received from that platform. The delta time should represent the number of hops and/or retries the mesh network took to deliver a message to the sensor platform and get a response back. (c) The last transmitted message string and a list of all the received messages.

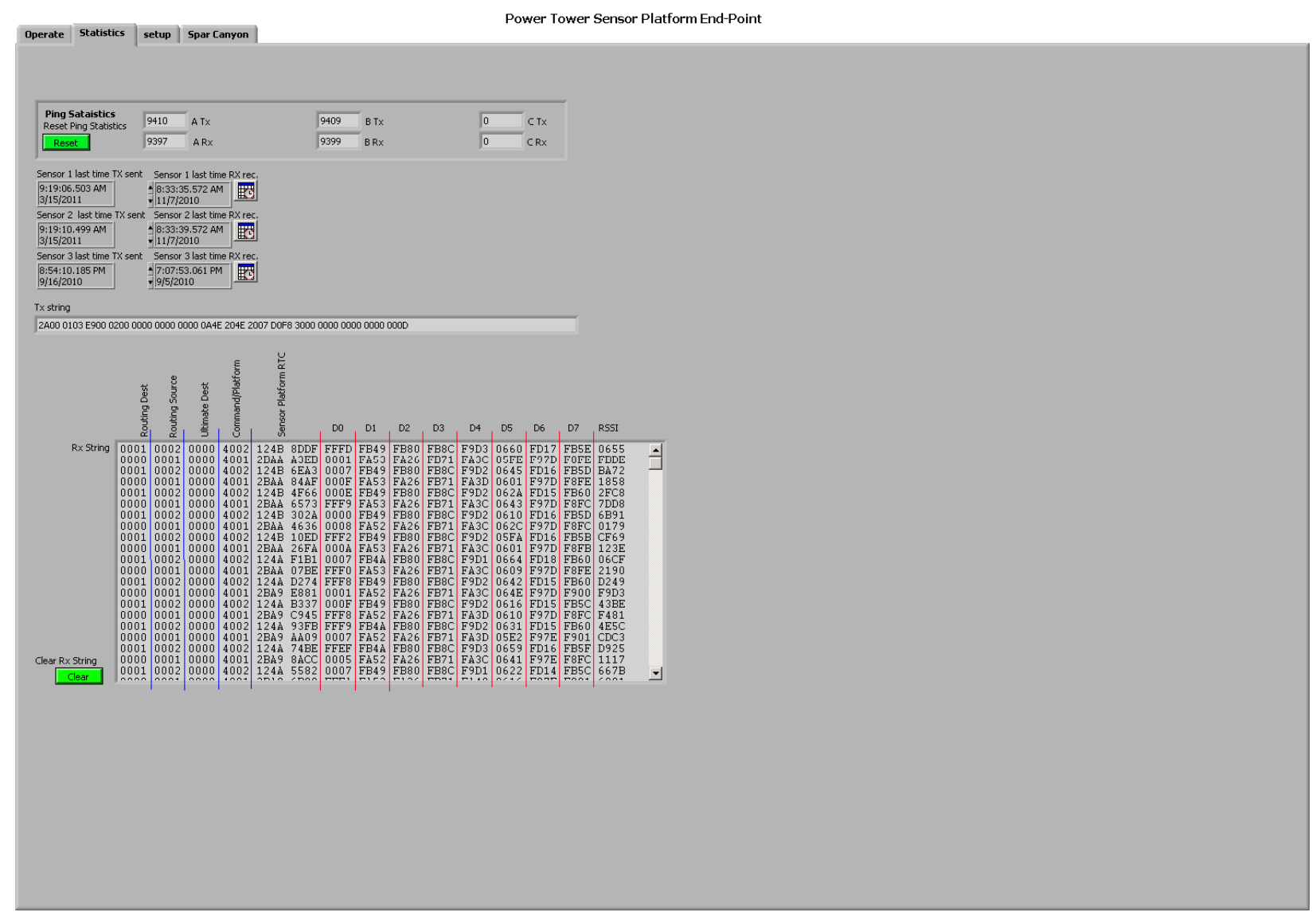

Figure B-2. Statistics tab.

The Setup tab (Figure B-3) displays system configuration information and allows for configuration changes to both the application and sensor platforms. Information displayed includes: (a) The PC port and baud rate that the endpoint communicates to the application with. (b) The complete configuration information (conversion coefficients, platform MAC addresses and identification information, alarm setpoints, etc.) used by the application to convert sensor measurements to engineering units and configure each sensor platform. (c) Controls to send a single command to the sensor platform. (d) Controls to periodically send commands to multiple platforms. (e) Control to save all sensor responses to disk file. 


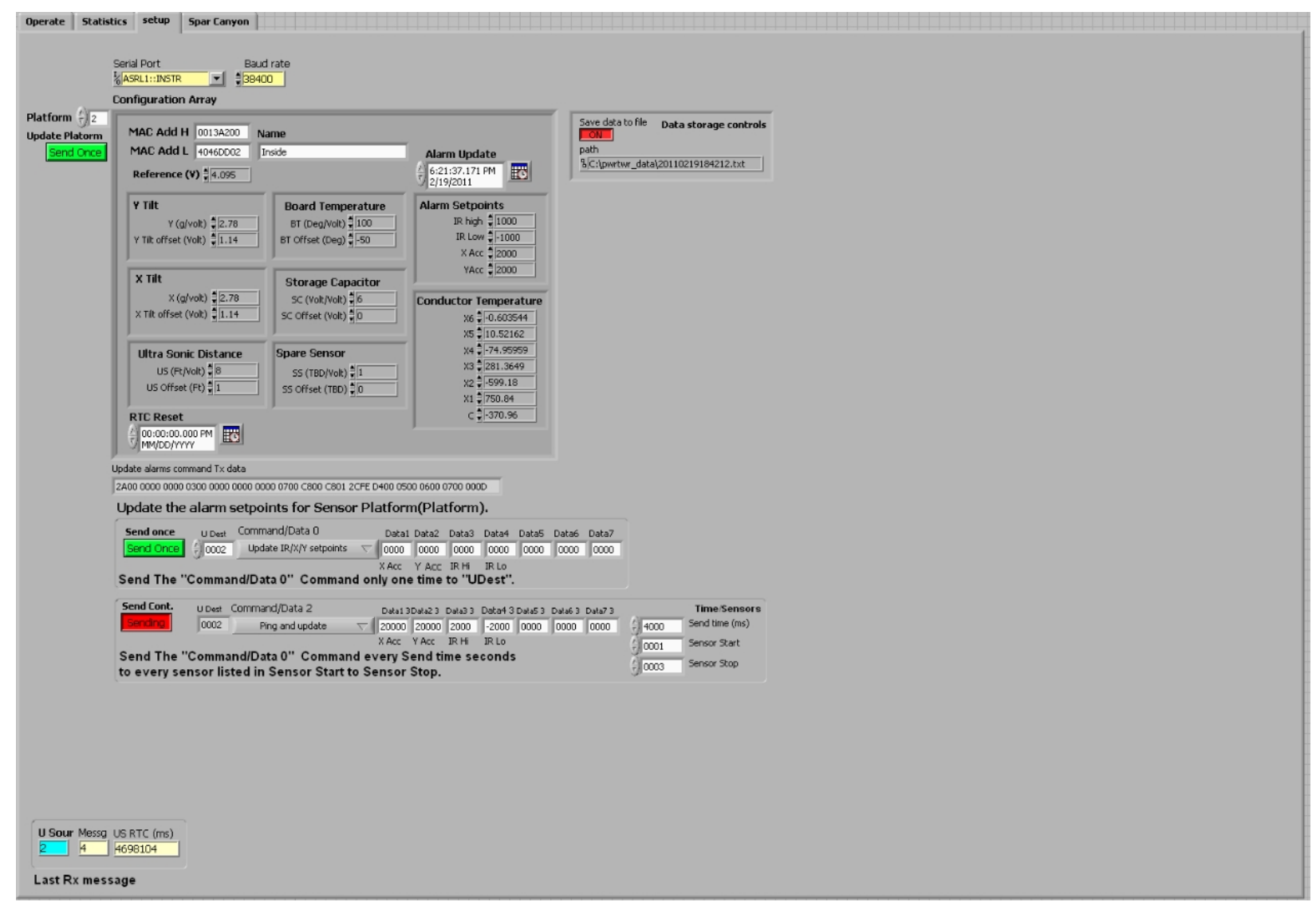

Figure B-3. Setup tab.

A fourth tab "Spar Canyon" not shown was intended to act as a prototype operator interface but was not implemented. 
Appendix C

\section{Tower Impact Testing Vibration Spectrum}




\section{Appendix C}

\section{Tower Impact Testing Vibration Spectrum}

Section 3.3.1, "Vibration Tests", discusses the tower impact testing performed at Buckeye, Arizona. Only some of the data sets were presented in this section. Appendix C presents the impact data sets collected on all four legs. Reference Section 3.3.1 for a description of the 3D data sets presented in this Appendix.

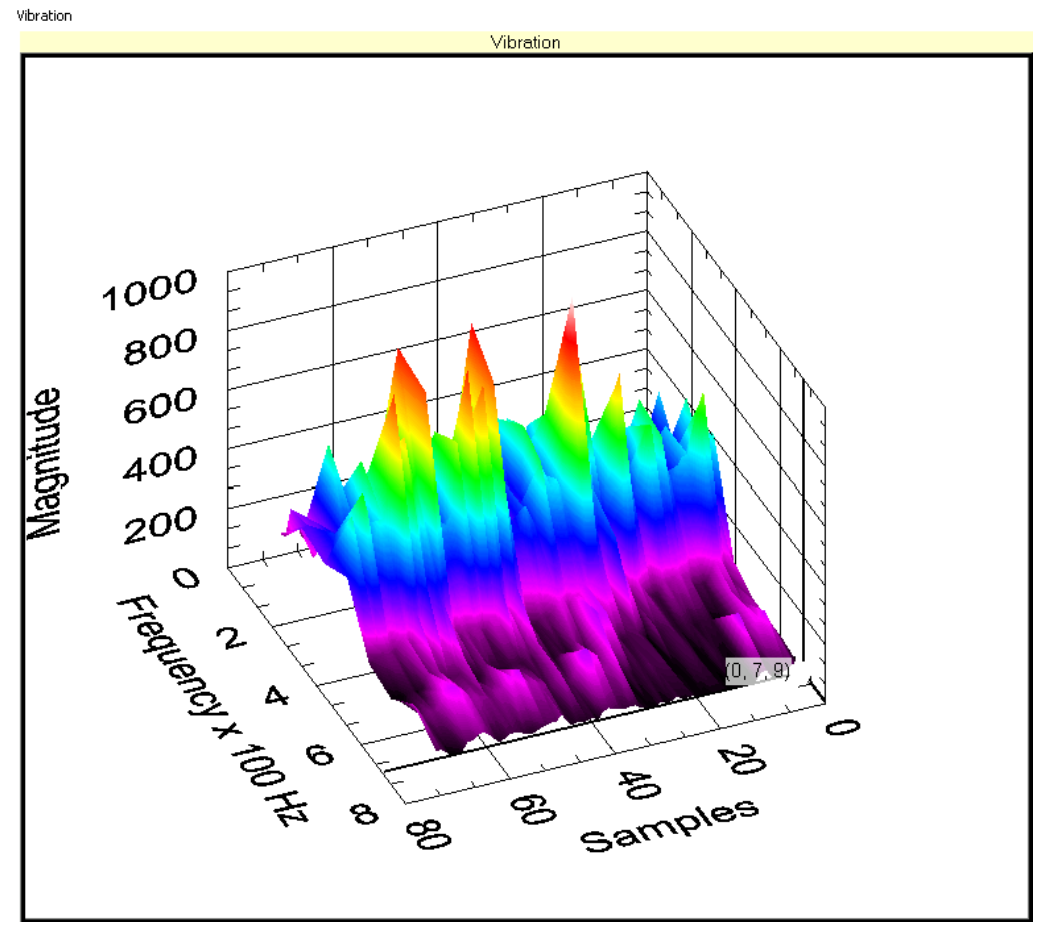

Figure $\mathrm{C}-1$. Southwest leg, west face, 1 meter, 5.3 and 11.4 joule impulse. 


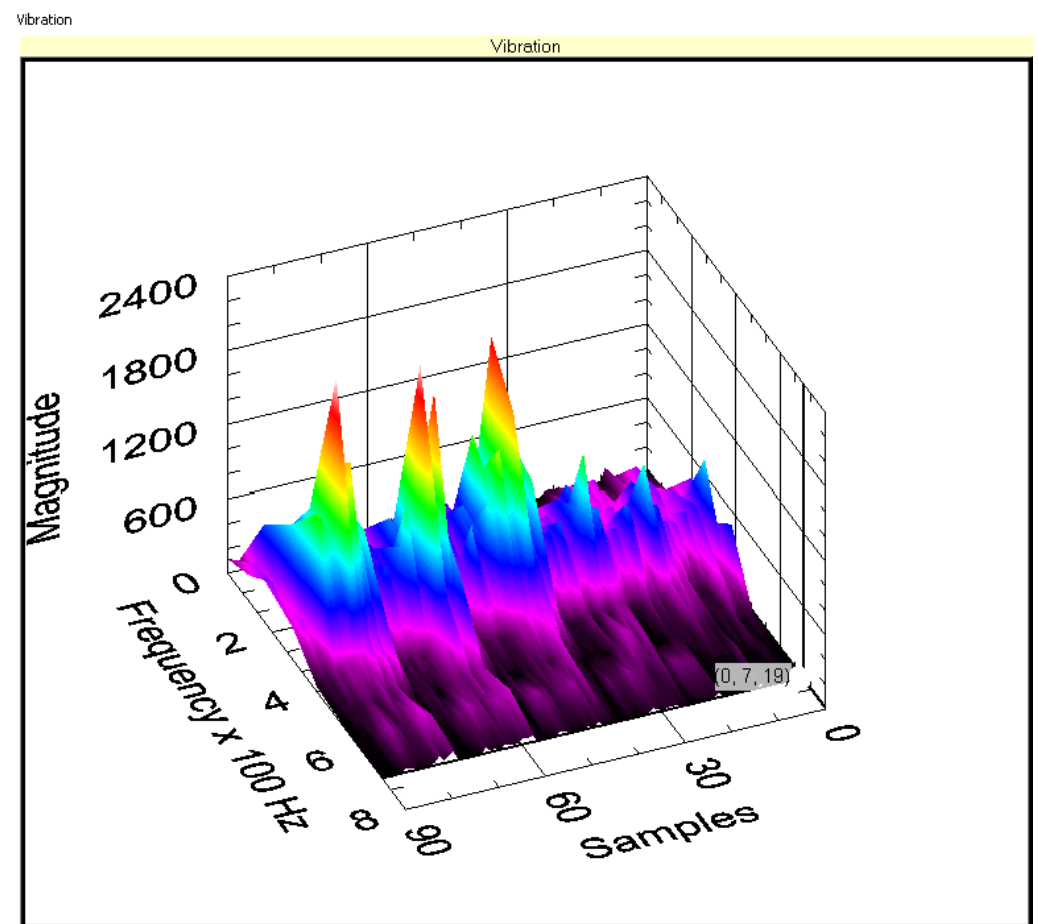

Figure $\mathrm{C}-2$. Southwest leg, south face, 1 meter, 5.3 and 11.4 joule impulse.

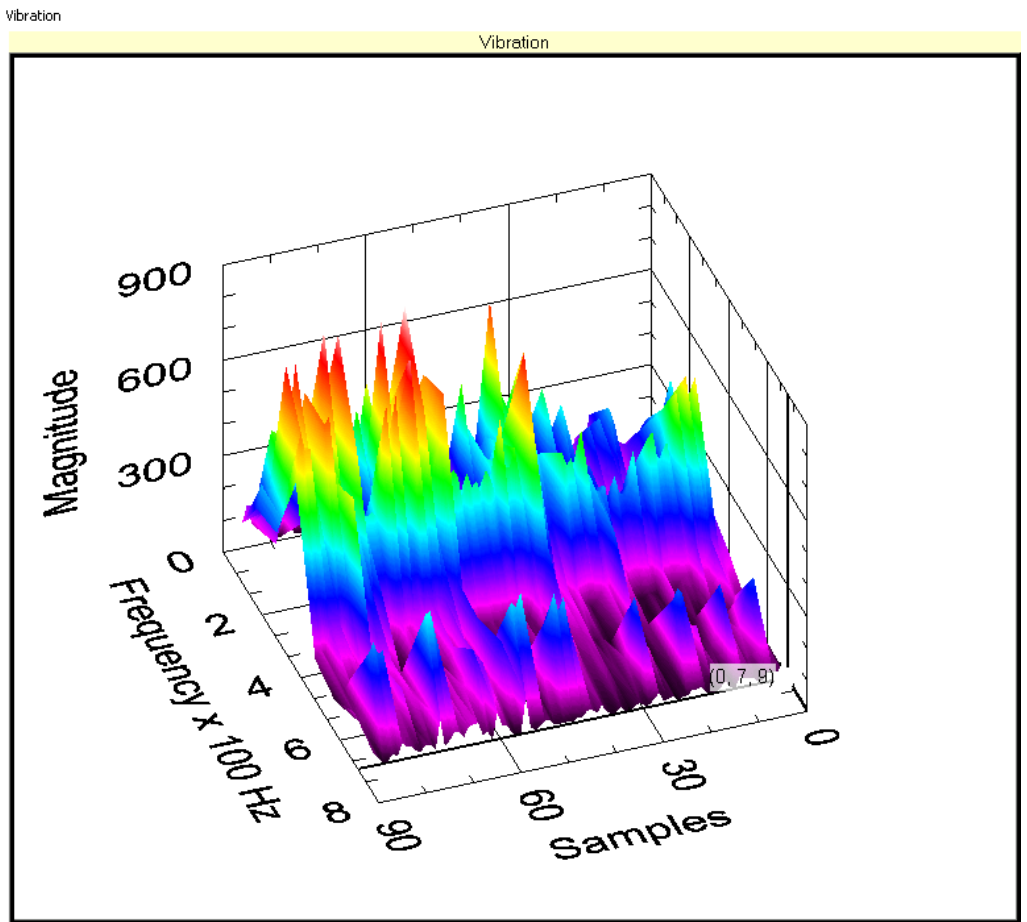

Figure C-3. Northwest leg, north face, 1 meter, 5.3 and 11.4 joule impulse. 


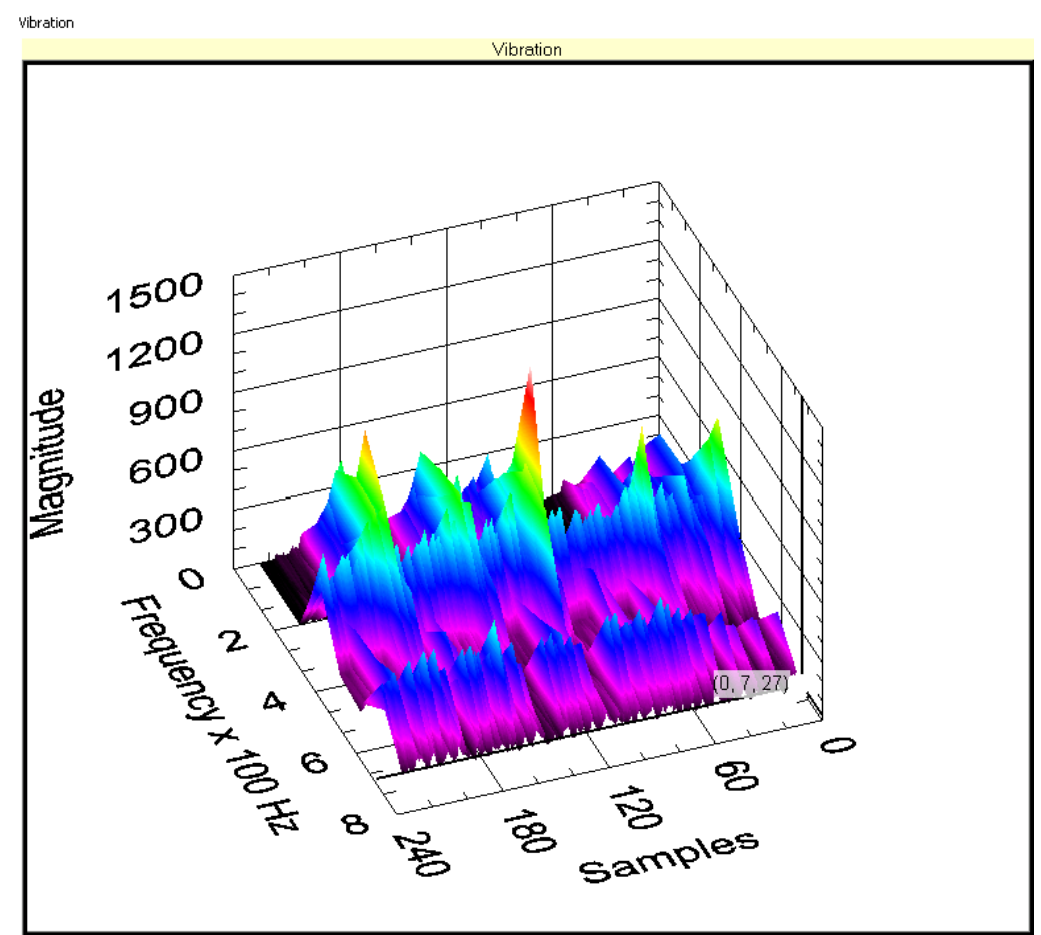

Figure $\mathrm{C}-4$. Northwest leg, west face, 1 meter, 5.3 and 11.4 joule impulse.

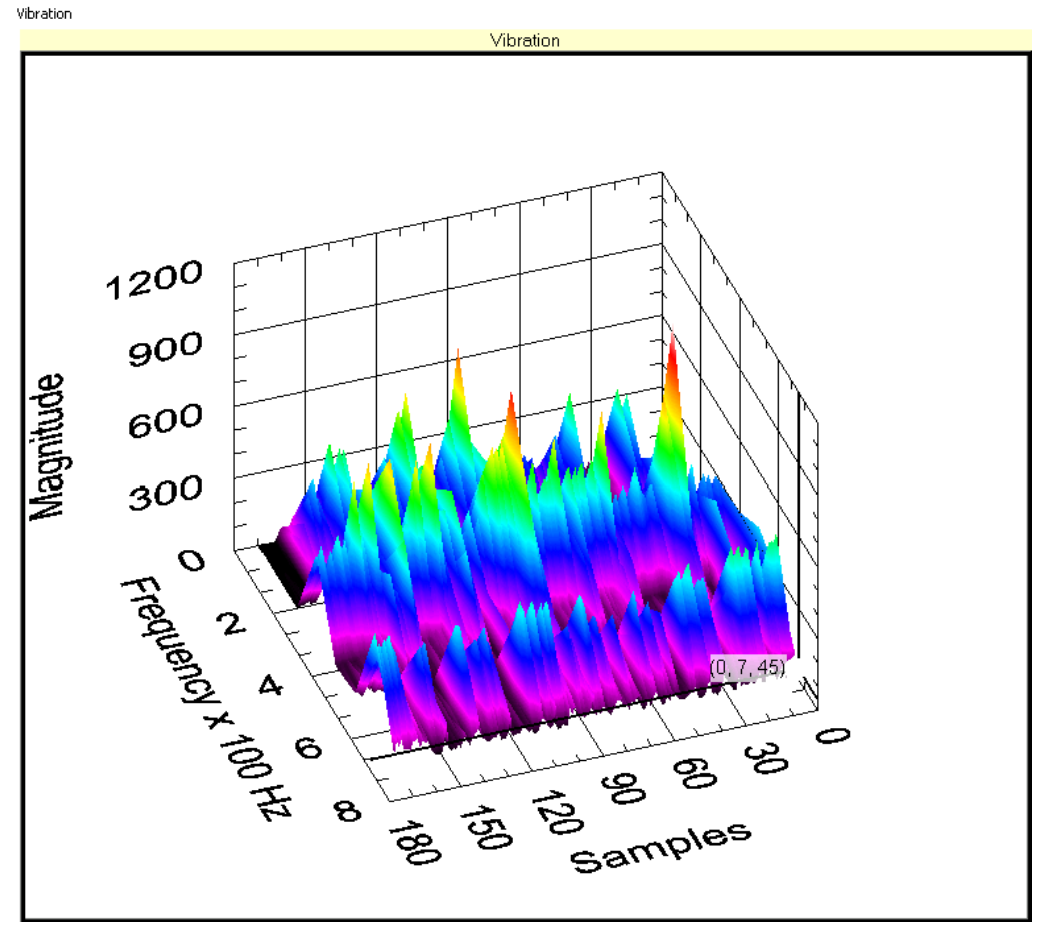

Figure $\mathrm{C}-5$. Northeast leg, north face, 1 meter, 5.3 and 11.4 joule impulse. 


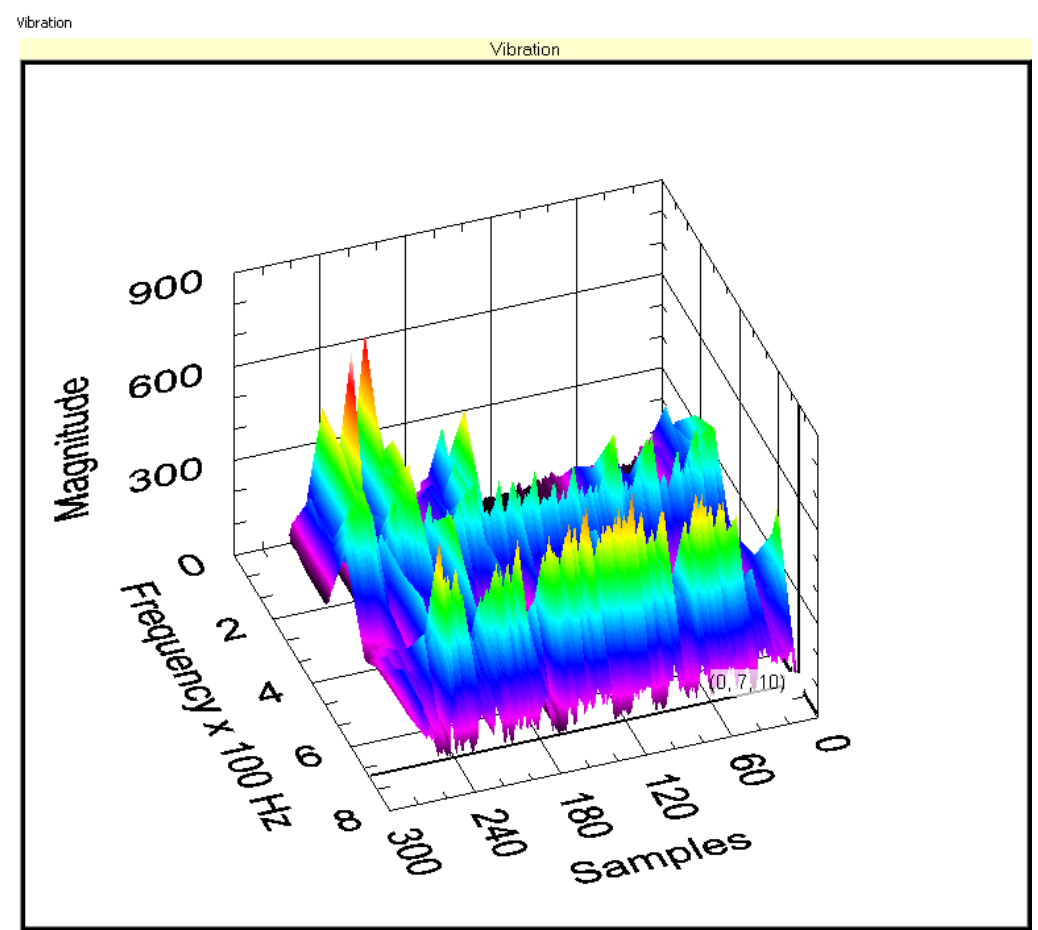

Figure C-6. Northeast leg, east face, 1 meter, 5.3 and 11.4 joule impulse.

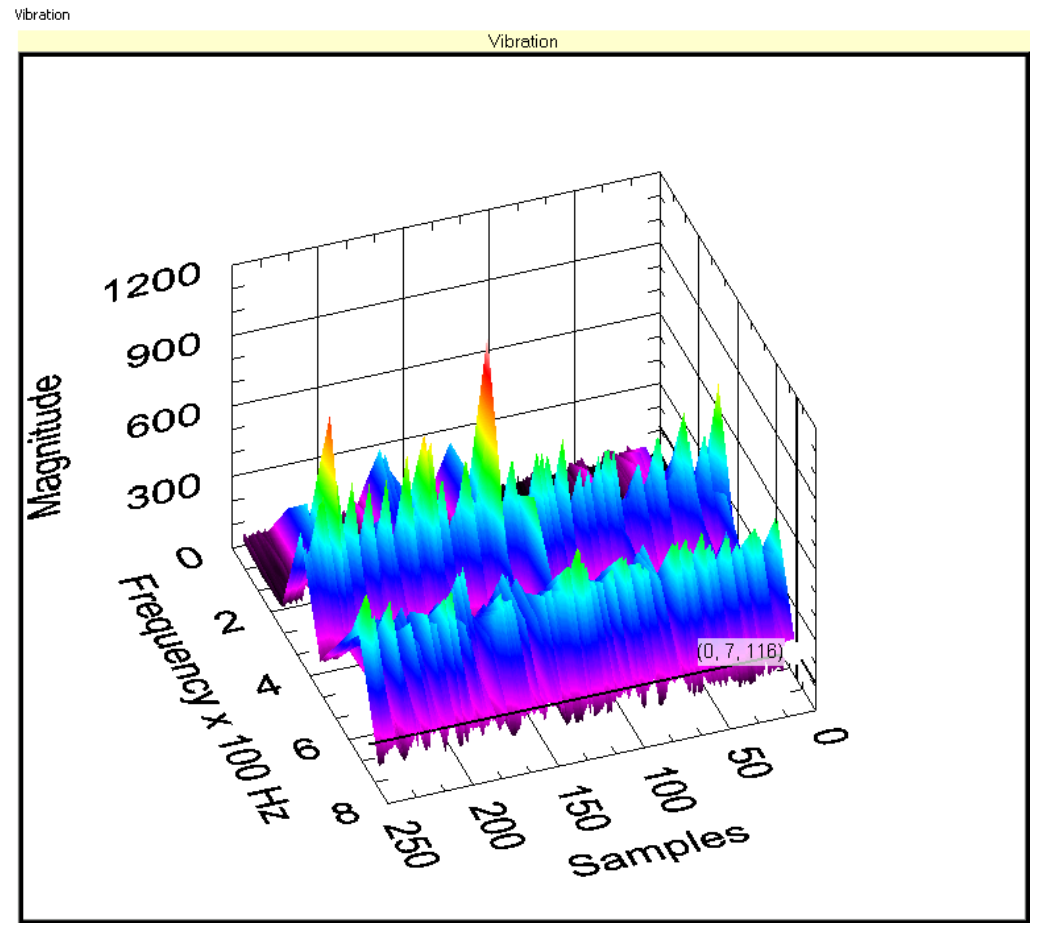

Figure C-7. Southeast leg, east face, 1 meter, 5.3 and 11.4 joule impulse. 


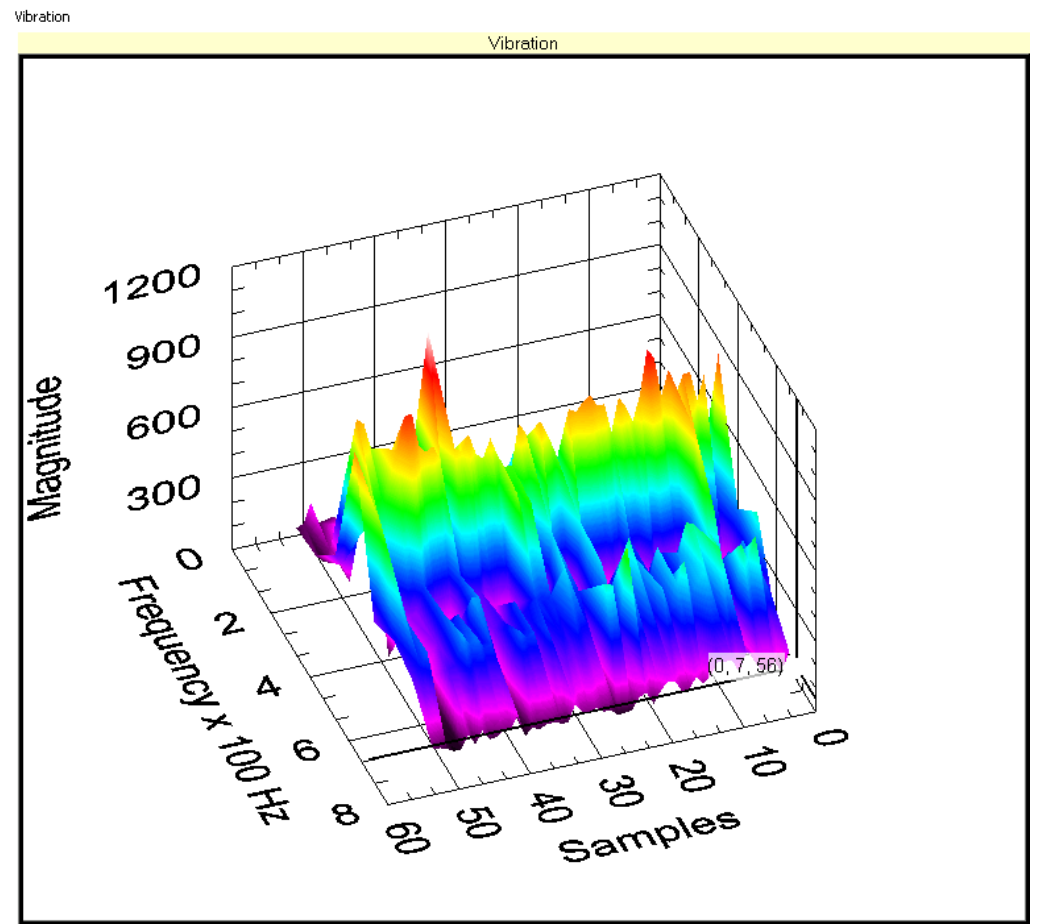

Figure $\mathrm{C}-8$. Southeast leg, east face, 1 meter, 5.3 and 11.4 joule impulse.

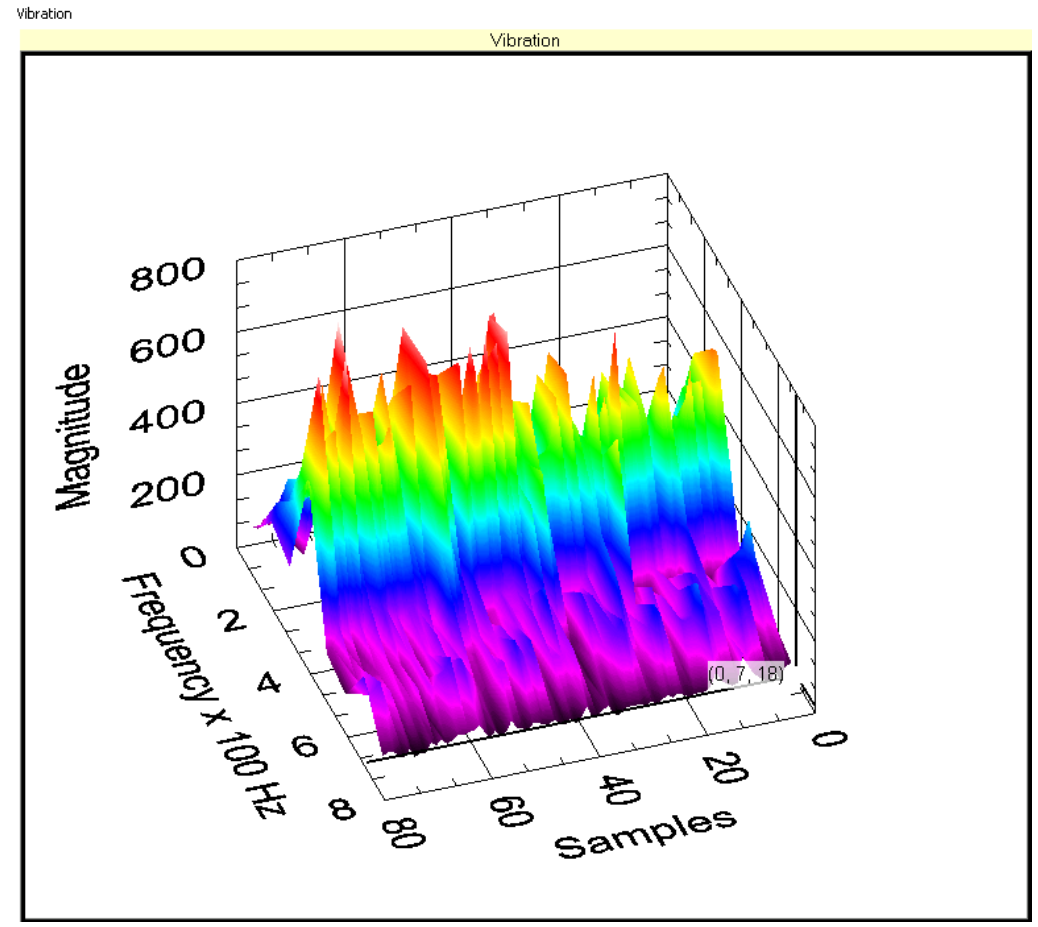

Figure C-9. Southeast leg, east face, 1 meter, 5.3 and 11.4 joule impulse repeat. 


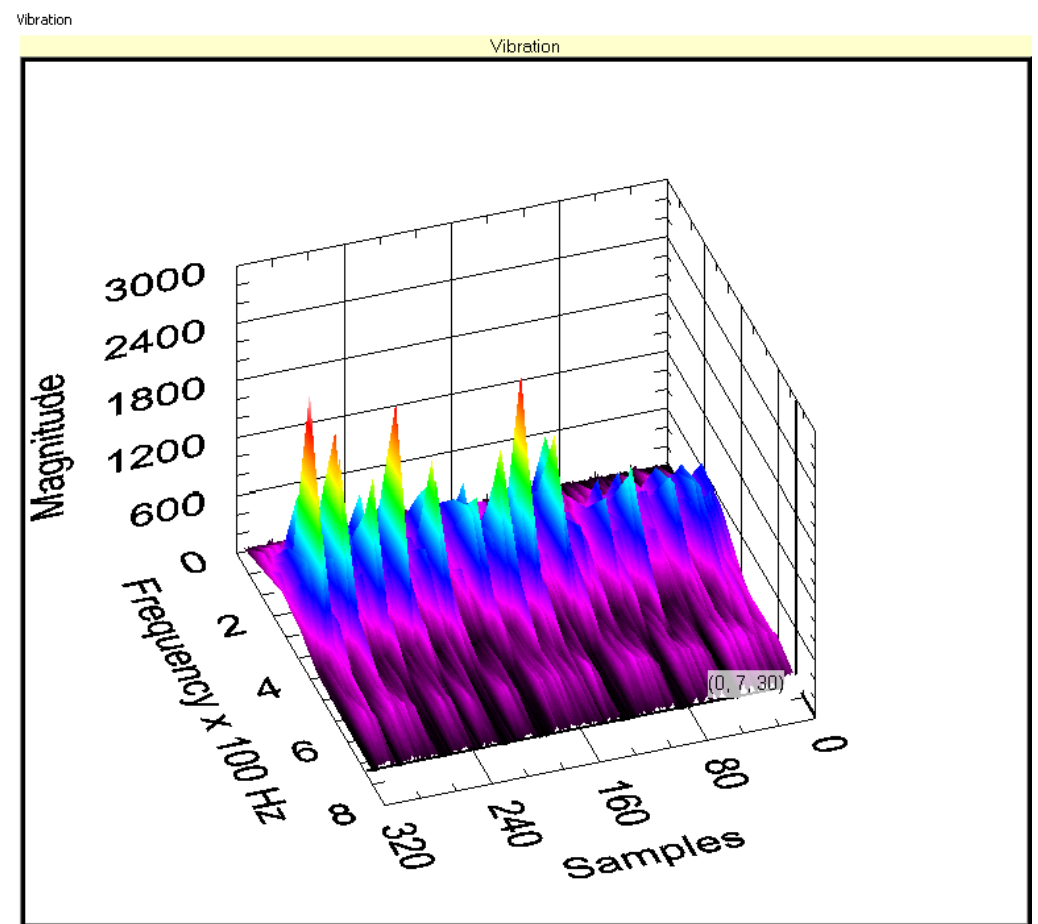

Figure C-10. Southwest leg, west face, 1.47 meter, 5.3 and 11.4 joule impulse repeat.

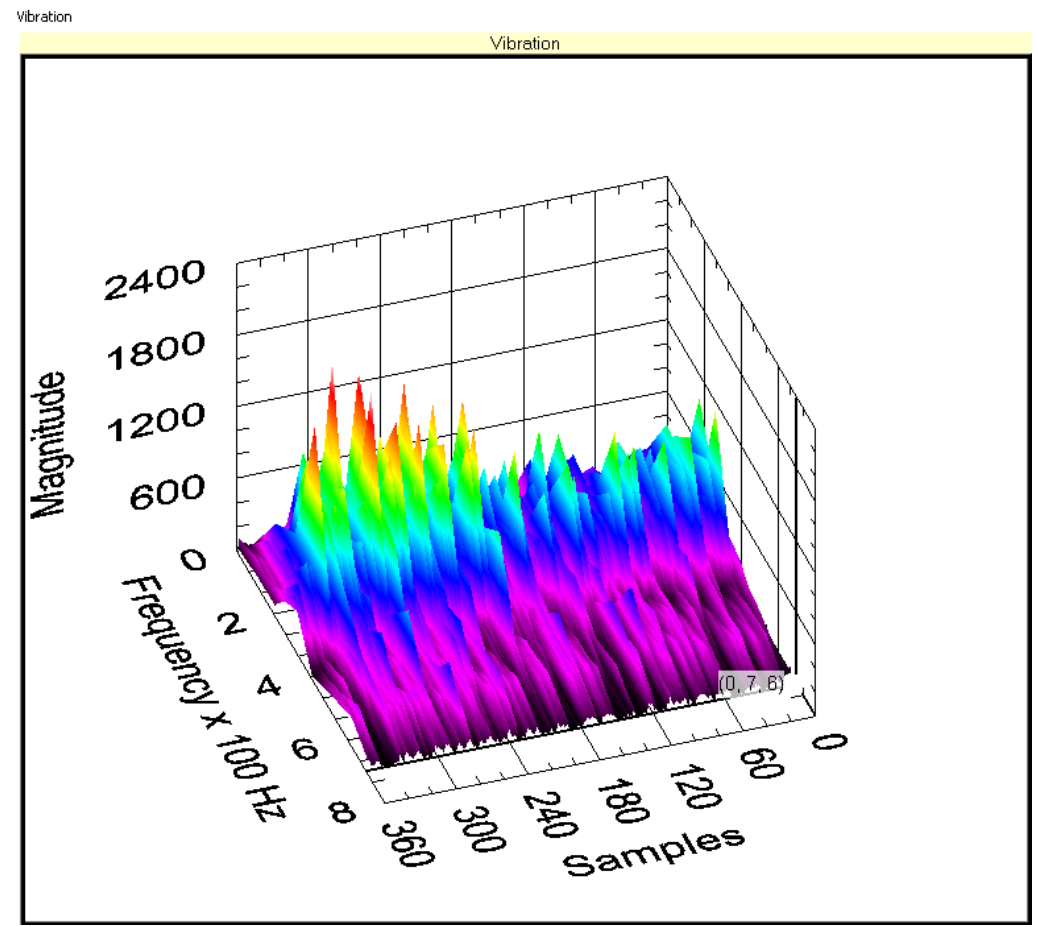

Figure $\mathrm{C}-11$. Southwest leg, west face, 0.4 meter, 5.3 and 11.4 joule impulse repeat. 